\title{
Executive Function, Neural Circuitry, and Genetic Mechanisms in Schizophrenia
}

\author{
Daniel Paul Eisenberg ${ }^{1}$ and Karen Faith Berman ${ }^{\star, 1}$ \\ ${ }^{1}$ Section on Integrative Neuroimaging and Clinical Brain Disorders Branch, Genes, Cognition, and Psychosis Program, \\ National Institute of Mental Health, NIH, DHHS, Bethesda, MD, USA
}

\begin{abstract}
After decades of research aimed at elucidating the pathophysiology and etiology of schizophrenia, it has become increasingly apparent that it is an illness knowing few boundaries. Psychopathological manifestations extend across several domains, impacting multiple facets of real-world functioning for the affected individual. Even within one such domain, arguably the most enduring, difficult to treat, and devastating to long-term functioning - executive impairment-there are not only a host of disrupted component processes, but also a complex underlying dysfunctional neural architecture. Further, just as implicated brain structures (eg, dorsolateral prefrontal cortex) through postmortem and neuroimaging techniques continue to show alterations in multiple, interacting signaling pathways, so too does evolving understanding of genetic risk factors suggest multiple molecular entry points to illness liability. With this expansive network of interactions in mind, the present chapter takes a systems-level approach to executive dysfunction in schizophrenia, by identifying key regions both within and outside of the frontal lobes that show changes in schizophrenia and are important in cognitive control neural circuitry, summarizing current knowledge of their relevant functional interactions, and reviewing emerging links between schizophrenia risk genetics and characteristic executive circuit aberrancies observed with neuroimaging methods.

Neuropsychopharmacology Reviews (2010) 35, 258-277; doi: 10.1 1038/npp.2009. I I; published online 19 August 2009
\end{abstract}

Keywords: schizophrenia; cognition; executive function; working memory; neuroimaging; genetics

\section{INTRODUCTION}

Psychiatry has long appreciated deficits in higher-order thought processes in schizophrenia, with relative sparing of many basic cognitive abilities (Kraepelin, 1909-1913), and indeed, the modern era of neuropsychological research has accumulated data from schizophrenic patients showing significant impairments in complex tasks requiring a range of advanced cognitive processes, collectively described as executive functions (Bozikas et al, 2006; Carter et al, 2001; Tan et al, 2006; Weinberger et al, 1986). Executive functions rely heavily on frontal lobe structures and include: directed attention and inhibition, task management, planning, monitoring, and coding of representations in working memory (Smith and Jonides, 1999). Subsets of these functions have shown a close relationship to both negative symptoms (O'Leary et al, 2000; Pantelis et al, 2001), thought disorder (Perlstein et al, 2001; Stirling et al, 2006), and

${ }^{*}$ Correspondence: Dr KF Berman, Section on Integrative Neuroimaging, National Institute of Mental Health, NIH, 9000 Rockville Pike, Building 10, Room 3C209, Bethesda, MD 20892-1365, USA, Tel: + 1301402 5483, Fax: + 1301496 7437, E-mail: karen.berman@nih.gov

Received 24 May 2009; revised 20 July 2009; accepted 21 July 2009 functional outcomes in schizophrenia (Kurtz et al, 2005; Liddle, 2000), in line with the suggestion that frontal lobe dysfunction is crucially important in schizophrenic psychopathology (Elvevag and Goldberg, 2000; Weinberger et al, 1994). Accumulated evidence from over two decades of neuroimaging experiments has confirmed executive-taskrelated functional abnormalities of the prefrontal cortex in schizophrenia; however, despite the numerous replications of this finding, the precise nature of illness-related frontal local circuit aberrancies contributing to executive dysfunction remains incompletely defined and remains the focus of ongoing investigation. Furthermore, because (1) functional abnormalities in schizophrenia are not exclusive to the frontal cortex, and (2) executive processes, though heavily reliant on the frontal cortex, also require cooperation from structures outside of the frontal lobes, schizophrenia research has increasingly turned its eye toward discerning how extended neural circuit dynamics contribute to illnessrelated cognitive phenotypes. Ultimately, if both these local prefrontal and extended distributed network characteristics in schizophrenia are relevant to the neurobiology of this disorder, then it may be possible to examine these systems through the lens of genetics. As schizophrenia likely 
involves multiple molecular pathways, this approach is invaluable in clarifying the mechanistic steps between risk genes, neuronal cellular function, neural circuits, and clinical morbidity. This chapter reviews the contributions of regions implicated in both schizophrenia and executive processing to local and extended neural circuits as well as describes recent advances in understanding relationships between these circuits and schizophrenia risk genes. Emphasis is placed on seven interconnected brain regions that have each prominently shown: (1) neuropathological and/or neurophysiological abnormalities in schizophrenia, (2) relevance to executive functioning and aberrant activity during executive processing in schizophrenia, and (3) abnormal functional relationships with other included regions during executive processing in schizophrenia. Additionally, nine genes are highlighted, each with variation showing both (1) evidence for contribution to risk of schizophrenia and (2) association with schizophrenia executive neuroimaging phenotypes that include circuits involving the emphasized regions.

\section{EXECUTIVE CIRCUITS WITHIN THE FRONTAL LOBES}

Ever since seminal regional blood flow studies showing specific and replicable frontal lobe dysfunction during executive task challenge in schizophrenia (Berman et al, 1986; Weinberger et al, 1986), better characterization of executive control circuits within the frontal lobes has remained at the forefront of schizophrenia research efforts. Investigations of abstract rule inference (Berman et al, 1995; Buchsbaum et al, 2005; Monchi et al, 2001), conflict management and monitoring (Macdonald et al, 2000; Pardo et al, 1990), verbal fluency (Frith et al, 1991; Gourovitch et al, 2000), and working memory (Cohen et al, 1997; Tsuchida and Fellows, 2009) in healthy individuals consistently show reliance on key frontal regions, most notably, the dorsolateral, ventrolateral, and anterior cingulate cortices. Abnormal functional measures in each of these regions have been shown in schizophrenia during these same paradigms (Becker et al, 2008; Berman et al, 1986; Callicott et al, 2003b; Kerns et al, 2005; Spence et al, 2000; Weinberger et al, 1986), bolstering the hypothesis of frontal primacy in schizophrenic pathophysiology (Elvevag and Goldberg, 2000; Weinberger et al, 1994) but increasing the imperative to understand how these disparate frontal nodes interact in concert during illness.

\section{Dorsolateral Prefrontal Cortex}

Numerous lines of evidence converge to implicate abnormalities of the dorsolateral prefrontal cortex (DLPFC) - the prototypical center of higher-order cognitive processing - in schizophrenia pathophysiology. Though they have neither shown gross evidence of degeneration (eg, gliosis) nor a diagnostic lesion, postmortem studies of schizophrenia patient DLPFC tissue have nonetheless shown support for perturbations of excitatory cells: increased pyramidal cell density (Selemon et al, 1995, 1998), reduced pyramidal neuron dendritic spine density (Glantz and Lewis, 2000), altered NMDA receptor subunit expression (Akbarian et al, 1996); inhibitory cells: reduced GAD67 and GAT1 mRNA expression (Akbarian et al, 1995; Volk et al, 2000); and dopaminergic afferents: reduced tyrosine hydroxylase expressing afferent axons (Akil et al, 1999), reduced DARPP-32 concentrations (Albert et al, 2002; Ishikawa et al, 2007). To what degree each of these and other cellular pathological findings are primary effects or secondary to other local disturbances (eg, other cellular pathological changes) or more distant alterations (eg, abnormal afferents from other frontal lobe structures or extrafrontal structures, Wang and Deutch, 2007) requires dedicated future study.

In vivo patient studies have further substantiated DLPFC pathological changes. Complimentary data from both region of interest (ROI) studies (Andreasen et al, 1994b; Nopoulos et al, 1995) and voxel-based morphometric studies (Cannon et al, 2002; Fornito et al, 2009; Giuliani et al, 2005) have reported statistically reduced DLPFC volumes in schizophrenia. Though not as consistently reported as reduced medial temporal lobe volumes (Honea et al, 2005), this finding, in concert with increased neuronal density, has been interpreted as a result of decreased DLPFC neuropil (Selemon et al, 1998). Importantly, reduced DLPFC gray matter volume is significantly more pronounced in patients with greater executive dysfunction, as measured by the Wisconsin Card Sorting Test (Rüsch et al, 2007). Neuronal measures of the DLPFC in schizophrenia have also shown abnormalities, particularly reduced $\mathrm{N}$-acetylapartate (NAA), a measure of neuronal integrity, which has been repeatedly found in magnetic resonance spectroscopy studies (Abbott and Bustillo, 2006) and has shown relevance to cognitive function in schizophrenia: NAA levels in patients show a positive correlation with the degree of DLPFC working memory activation as measured by $\left[{ }^{15} \mathrm{O}\right] \mathrm{H}_{2} \mathrm{O}$ PET (Bertolino et al, 2000b). Notably, DLPFC $\mathrm{D}_{1}$ receptor binding, measured by $\left[{ }^{11} \mathrm{C}\right] \mathrm{NNC} 112 \mathrm{PET}$ in medication-free schizophrenic patients, has been shown to be both increased and correlated with working memory impairment in schizophrenia (Abi-Dargham et al, 2002). When measured with $\left[{ }^{11} \mathrm{C}\right] \mathrm{SCH} 23390$, however, $\mathrm{D}_{1}$ binding in the prefrontal cortex appears reduced (Okubo et al, 1997). Interestingly, these conflicting data actually correspond well with rodent models of subchronic dopaminergic depletion, which increases $\left[{ }^{11} \mathrm{C}\right] \mathrm{NNC} 112$ binding but paradoxically decreases $\left[{ }^{11} \mathrm{C}\right] \mathrm{SCH} 23390$ binding (Guo et al, 2003) and are hypothesized to reflect compensatory responses to reduced prefrontal dopaminergic input from the midbrain. White matter abnormalities of the DLPFC have also been described (Schlösser et al, 2007). Taken together, these cytopathological, structural, and neuroreceptor mapping findings predict both a prominent role for disrupted dorsolateral prefrontal cortical function and related aberrant interactions between this region and other brain structures contributing to executive dysfunction in schizophrenia. 
In line with the former assertion, a plethora of functional imaging studies of schizophrenia have shown alterations in DLPFC physiology in response to executive cognitive demands. Replication of reduced relative frontal activity (Ingvar and Franzén, 1974), in the DLPFC during executive tasks, has been frequent in the past two decades, and has been observed in medicated, medication-free, and medication-naïve patients (Barch et al, 2001, 2003; Berman et al, 1986, 1992; Callicott et al, 1998; Camchong et al, 2006; Cannon et al, 2005; Cantor-Graae et al, 1991; Carter et al, 1998; Catafau et al, 1994; Curtis et al, 1998; Driesen et al, 2008; Fletcher et al, 1998; Glahn et al, 2005; Goldberg et al, 1990; Liu et al, 2002; Mcdowell et al, 2002; MeyerLindenberg et al, 2001, 2002; Parellada et al, 1994, 1998; Perlstein et al, 2001; 2003; Ragland et al, 1998; Rubia et al, 1994; 2001; Schlösser et al, 2007; Steinberg et al, 1996; Volz et al, 1997; Weinberger et al, 1986; Yurgelun-Todd et al, 1996). Furthermore, there is evidence that the DLPFC dysfunction as described in schizophrenia is not solely explained by attentional or global cognitive impairment (Berman et al, 1988), nor is it a result of neuropsychiatric illness, generally, as patients with major depression (Barch et al, 2003; Berman et al, 1993) and Huntington's (Goldberg et al, 1990) do not exhibit this finding. However, abnormally increased DLPFC activation has also been reported (Callicott et al, 2003b; Manoach et al, 1999; 2000; Potkin et al, 2009; Thermenos et al, 2005), often in fMRI studies of higher performing patient cohorts, and has been consequently labeled as inefficient prefrontal processing (Callicott et al, 2003b; Manoach et al, 1999; Potkin et al, 2009) because greater activation is required to achieve a given performance level. Notably, some studies have found that better performing patients show more hyperactivation in the DLPFC whereas poorer performing patients hypoactivate the DLPFC (Callicott et al, 2003b; Karlsgodt et al, 2007, 2009; Manoach et al, 2000); however, even this behavioral-physiological relationship shows variability, being susceptible to dopaminergic manipulation (Daniel et al, 1991) and may differ from healthy volunteers (Karlsgodt et al, 2009). Reconciliation of these findings remains a matter of debate, but several authors have proposed that they rest in part on variation in task demands and individual performance capacities. This hypothesis features an inverted U-shaped load-response curve, such that as task demands increase, activation initially rises until physiological capacity is reached, after which, activation falls (Fletcher et al, 1998). In schizophrenia, this curve may be shifted to the left (Jansma et al, 2004; Perlstein et al, 2003), resulting in hyperactivation (ie, inefficient signal) at lower relative task loads (where performance matching with healthy volunteers is more attainable) and hypoactivation (ie, inadequate signal) at higher relative task loads (where performance is likely to be significantly worse in schizophrenia) (Callicott et al, 2003b; Manoach 2003). This curve may also be flattened in patients, resulting in less neural response to varying load levels (Johnson et al,
2006). Thus, more activation is not always better; rather, its significance depends on individual capacity and task load. Other investigations have emphasized the impact of greater morphological variability in schizophrenia. Such variability can affect the topographical distribution of activation patterns, which, in turn, can weaken group-averaged data for a given region, despite potentially equivalent or stronger activations at the individual level (Manoach, 2003; Park et al, 2004). Additional factors, such as specific task paradigm characteristics (Barbalat et al, 2009; Curtis et al, 1999; Holmes et al, 2005; Macdonald et al, 2005; Quintana et al, 2003), clinical heterogeneity, and medication status (see Weiss et al, 2003 versus Weiss et al, 2007, showing greater activation during a modified Stroop paradigm when medicated patients were studied, but the opposite finding when a separate cohort of unmedicated patients was studied), may also have a role. Regardless of the cause of directional discrepancies, because most studies of DLPFC connectivity (covariance with activity in other brain regions) show abnormal disconnection with other neocortical structures important for executive function (Bassett et al, 2008; Kim et al, 2003; Schlösser et al, 2003; Spence et al, 2000; Tan et al, 2006; Whitfield-Gabrieli et al, 2009; Wolf et al, 2007; Woodward et al, 2009; Yasuno et al, 2005) and because even patients who overactivate the DLPFC still often do not achieve a higher performance on executive tasks than their healthy control comparators, it is clear that DLPFC is dysfunctional in schizophrenia. In the context of the cellular pathological, structural, and neuroreceptor imaging DLPFC findings, such altered DLPFC physiology seems to be an expected and robust illness-related phenotype reflecting reduced neurophysiological resources in which microcircuits are either overtaxed or overwhelmed.

\section{Ventrolateral Prefrontal Cortex}

Though less well studied in schizophrenia than the DLPFC, the ventrolateral prefrontal cortex (VLPFC), judged to be preferentially involved in working memory storage and rehearsal processes rather than information manipulation (Wager and Smith, 2003), may show less cellular abnormalities. For instance, the increased density of pyramidal neurons in DLPFC does not seem to exist in the VLPFC (Selemon et al, 2003). Nonetheless, activation differences have been reported in schizophrenia during executive tasks including working memory (Callicott et al, 2003b; Scheuerecker et al, 2008; Schneider et al, 2007; Stevens et al, 1998; Tan et al, 2005), motor response inhibition (Kaladjian et al, 2007), and attentional tasks (Schneider et al, 2007), raising the question of exactly how this region contributes to executive processing networks in psychotic illness. In line with the theory that VLPFC is recruited in a compensatory fashion during DLPFC-taxing tasks in schizophrenia, patients have shown increased VLPFC activation in conjunction with reduced DLPFC activation during manipulation in a verbal working memory task (Tan et al, 2005). 
More recent data examining functional connectivity suggest that this potential compensatory mechanism cannot simply be described as increased relative activation, but rather, increased dominance and assumption of DLPFC's nodal role in extended executive circuitry. Tan et al (2006), for instance, used the n-back working memory fMRI paradigm to show that high-performing healthy control subjects evidenced greater DLPFC relative to VLPFC activation with greater working memory load, whereas volunteers with schizophrenia showed the opposite pattern. Remarkably, in control subjects, DLPFC showed more robust functional connectivity with a posterior parietal region, whereas in patients, the VLPFC showed greater parietal functional connectivity (Tan et al, 2006). Of note, this echoes report of abnormally increased 'structural connectivity' (the correlation between gray matter volumes of two or more brain structures across individuals) between ventral prefrontal cortex and inferior parietal lobule (IPL) in schizophrenia (Buchanan et al, 2004). Likewise, these results are similar to findings from a word-encoding fMRI paradigm, in which schizophrenic patients showed reduced DLPFC-temporal and increased VLPFC-temporal functional connectivity (Wolf et al, 2007). Thus, increased VLPFC relative to DLPFC prominence in executive neural networks may characterize altered and often inadequate (by behavioral performance measures) circuit-level strategies in schizophrenia during DLPFC-activating executive tasks.

\section{Anterior Cingulate}

As in DLPFC, postmortem experiments in schizophrenia have identified alterations in the neurons of the anterior cingulate cortex (ACC), a paralimbic structure also within the frontal lobes. These include abnormalities in a wide range of proteins (Clark et al, 2006), increased glutamatergic vertical fibers - presumably associative afferents - in layers II and IIIa (Benes et al, 1992b), reduced layer IV pyramidal cell density (Benes et al, 2001), and a number of findings related to GABAergic neurons (Torrey et al, 2005), such as reduced concentration of neurons expressing GAD67 mRNA (Woo et al, 2004) but increased superficial layer $\mathrm{GABA}_{\mathrm{A}}$ receptor binding (Benes et al, 1992a), though this last finding was not seen in receptor imaging studies in vivo (Verhoeff et al, 1999). Corroborating experiments using structural and spectroscopic MRI have further documented reductions in anterior cingulate volume (Baiano et al, 2007; Goldstein et al, 1999), gray matter concentration (Kubicki et al, 2002; Meda et al, 2008; Rüsch et al, 2007), and NAA levels (Wood et al, 2007), as well as increased glutamine (Theberge et al, 2002). Additionally, PET studies have shown reduced $\mathrm{D}_{2 / 3}$ binding in this region (Buchsbaum et al, 2006; Suhara et al, 2002; Yasuno et al, 2005). Many of these volumetric (Szeszko et al, 2000), morphometric (Eack et al, 2008), spectroscopic (Ohrmann et al, 2008), and neuroreceptor (Ko et al, 2009; Lumme et al, 2007) indices have shown robust relationships with executive functioning in healthy control subjects.
In light of these findings, it is perhaps not surprising that executive functions reliant on anterior cingulate activity elicit abnormal ACC responses in schizophrenia. For example, during tasks that include conflict and error monitoring, subjects with schizophrenia show both worse performance (in select, but not all, studies: less error-related reaction time slowing, posterror behavioral adjustments and more errors) and less anterior cingulate activation (Andreasen et al, 1992; Carter et al, 1997, 2001; Dolan et al, 1995; Ford et al, 2004; Kerns et al, 2005; Krabbendam et al, 2009; Laurens et al, 2003; Polli et al, 2008; Rubia et al, 2001; Salgado-Pineda et al, 2004; Volz et al, 1999; Weiss et al, 2007; Yucel et al, 2002; but see Weiss et al, 2003), suggesting a deficit in self-monitoring processes required to signal conflicts between response and maintained rule representations (Macdonald et al, 2000). Similar reductions in anterior cingulate activation during verbal fluency tasks have also been reported in several (Boksman et al, 2005; Broome et al, 2009; Fletcher et al, 1996; Fu et al, 2005), but not all (Ragland et al, 2008), investigations. It is notable that dopamine agonist administration results in marked augmentation of ACC activation during verbal fluency in schizophrenia, but not healthy volunteers (Dolan et al, 1995), implicating either aberrant modulatory mesencephalic input to this region and/or postsynaptic dopaminergic signaling dysregulation in this region. Robust evidence for augmented basal ganglia sensitivity to dopamine agonists in schizophrenia (Abi-Dargham et al, 1998; Laruelle et al, 1996) offers circumstantial support for the former hypothesis. As the anterior cingulate shows heterogeneous functional topography, it is important to note that the majority of the above-cited findings localize to the dorsal anterior cingulate, consistent with a more cognitive specialization of this region (Drevets and Raichle, 1998), though a few reports also feature rostral anterior cingulate findings (Laurens et al, 2003; Polli et al, 2008), perhaps reflecting motivational components of task performance and monitoring (Polli et al, 2008). The absence of subgenual anterior cingulate cortical findings suggest that this region likely does not have an important function in executive task performance, in line with its predominantly affective role (Drevets and Raichle, 1998).

Given the above-cited cellular, structural, and functional abnormalities in ACC and DLPFC, effective neural cooperation between these structures in the service of executive processing in schizophrenia is critical but unlikely. Indeed, preclinical and clinical studies are both suggestive of disrupted DLPFC-ACC communication. Efferent projections from the anterior cingulate (BA32) synapse both on excitatory and inhibitory target cells in the supragranular layers of DLPFC (BA9), the latter being predominantly calbindin-positive GABAergic neurons (Medalla and Barbas, 2009) that inhibit distal pyramidal spines in the theorized service of dampening distracting stimuli (Wang et al, 2004). This is in contrast to projections within DLPFC regions (BA46 $\rightarrow$ BA9), in which inhibitory targets are less 
robust and more frequently calretinin-positive cells that synapse on inhibitory interneurons, thereby promoting disinhibitory effects on DLPFC pyramidal cells (Medalla and Barbas, 2009). Notably, the density of calbindinpositive, but not calretinin-positive, GABAergic neurons may be reduced in the superficial layers of the DLPFC in schizophrenia (Beasley et al, 2002; Sakai et al, 2008) but see (Daviss and Lewis, 1995; Tooney and Chahl, 2004), suggesting one potential basis for disrupted ACC-DLPFC neural transmission, resulting in increased noise at the level of higher-order cognitive representations (Winterer et al, 2004). Likewise, reciprocal connections from DLPFC and other cortical regions to the ACC may also be affected as suggested indirectly by superficial cortical layer abnormalities within the ACC (Benes et al, 1992a, b). Reduced white matter integrity (fractional anisotropy measured by DTI) in the cingulum bundle, which shows a relationship with impaired Wisconsin Card Sorting Task performance (Kubicki et al, 2003), offers another reason to predict altered communication between the anterior cingulate and prefrontal regions. In any case, frontocingulate functional dysconnectivity has been explicitly described during verbal fluency (Spence et al, 2000) and modified continuous performance tasks (Honey et al, 2005) in schizophrenia. Further, structural equation modeling of regional $D_{2 / 3}$ receptor binding has shown altered connectivity from other frontal cortical regions (as well as thalamus and parietal cortex) to the anterior cingulate (Yasuno et al, 2005).

\section{EXTENDED EXECUTIVE CIRCUITS}

Despite historical emphasis on frontal circuits in investigations aimed at understanding cognitive pathophysiology in schizophrenia, recent studies have amassed considerable evidence that a systems-level disruption, including but not limited to frontal cortical dysfunction, is at play. During executive tasks, functional neuroimaging of patients shows abnormal activation not only in the frontal lobes, but also similarly in other distributed brain regions typically recruited by executive task demands (Jansma et al, 2004). Several of these regions have also shown cellular, structural, or neurochemical abnormalities in schizophrenia and include (1) the IPL, which has consistently shown significant contributions to a range of executive functions in neurophysiological experiments and may be a particularly important support to frontal executive circuits as a working memory storage buffer (Jonides et al, 1998); (2) the medial temporal cortex/hippocampus, which may provide specific contextual/stimulus-stimulus association consolidation for abstract rule establishment during select executive tasks, such as the Wisconsin Card Sort (Graham et al, 2009), but is normally suppressed during other executive functions (eg, working memory); (3) the basal ganglia/ caudate, which is important for cognitive flexibility (Eslinger and Grattan, 1993), and along with the thalamus, may provide a gating function for prefrontal-bound information during working memory (Frank et al, 2001; Landau et al, 2009); and (4) the thalamus, which is an essential pathway within cortico-striatal-thalamic-cortical loops and shows prefrontal-like participation in workingmemory-related neural transmission (Tanibuchi and Goldman-Rakic, 2003). Furthermore, particular disturbances of communication among these and frontal regions, often measured through fMRI or PET functional connectivity methodologies, suggest inefficient circuit dynamics that may underlie executive dysfunction. Thus, studies in recent years have increasingly attended to extrafrontal regions both to show novel cellular and molecular biological markers of disease, and to understand the critical contributions of extrafrontal regions to these circuits.

\section{Inferior Parietal Lobule}

Though preclinical data implicating the IPL in schizophrenia are scarce, structural imaging findings in this region are not. Reductions in parietal gray matter volume in schizophrenia relative to healthy individuals have been reported in a handful of studies (Buchanan et al, 2004; Frederikse et al, 2000; Goldstein et al, 1999; Hulshoff Pol et al, 2001; Kubicki et al, 2002; Nierenberg et al, 2005; Schlaepfer et al, 1994; Wolf et al, 2008; Zhou et al, 2007) and are more pronounced in patients with passivity delusions (Maruff et al, 2005) and greater cognitive impairment (Wolf et al, 2008). Schizophrenia patients also show significantly greater structural variability (Yoon et al, 2006) and reversed or absent hemispheric asymmetry (Buchanan et al, 2004; Niznikiewicz et al, 2000; Zhou et al, 2007) in this region. Reductions in parietal white matter have also been found in patients with prominent negative symptoms (Zetzsche $e t$ al, 2008). It is notable that child onset schizophrenia patients show early and accelerated parietal volume loss over time (Thompson et al, 2001).

Regions in the IPL (BA 40), in addition to lateral prefrontal cortices and anterior cingulate, show reliable activation during prototypical executive function tasks, such as the Wisconsin Card Sorting Test, as well as during component executive processes, such as response inhibition and set shifting (Buchsbaum et al, 2005). In conjunction with structural imaging evidence for abnormalities in this area and executive dysfunction in schizophrenia, this would predict parietal functional deficits detectible during executive task performance. Indeed, akin to findings in the prefrontal cortex, reductions in parietal activation during working memory (Barch and Csernansky, 2007; Broome et al, 2009; Jansma et al, 2004; Kindermann et al, 2004; Schlagenhauf et al, 2008; Schlösser et al, 2007; Schneider et al, 2007), semantic integration (Kuperberg et al, 2008), and selective attention (modified Stroop) (Weiss et al, 2007) have been commonly observed in schizophrenia subjects (but see Lee et al, 2008; Ragland et al, 2008; Thermenos et al, 2005, showing increases). Recent data also suggest the possibility that hallucinating patients may have less 
working-memory-associated parietal activation than nonhallucinating patients (Wible et al, 2009).

The inferior parietal and prefrontal cortices share key involvement in executive processing and important anatomical connections. In view of both of these regions' structural and functional abnormalities in schizophrenia, it is likely that communication between these structures, particularly during executive tasks, is abnormal as well in patients. The superior longitudinal fasciculus, which links parietal and prefrontal cortical areas, shows reduced fractional anisotropy, a measure of white matter integrity, in schizophrenia (Shergill et al, 2007) suggestive of impaired prefrontal-parietal interactions. This notion has been advanced by several functional connectivity studies as well: for instance, DLPFC-IPL connectivity during the n-back working memory task is reduced in schizophrenia (Kim et al, 2003; Tan et al, 2006), though the results of two other studies have been mixed (Barch and Csernansky, 2007; Schlosser et al, 2003). Similarly, during a choice reaction-time test (Woodward et al, 2009) and the $\mathrm{AX}$ version of the continuous performance task (Yoon et al, 2008), both of which require less executive resources than the n-back working memory test, prefrontal-IPL connectivity is also reduced in schizophrenia. Even resting state regional glucose metabolism shows this pattern (Mallet et al, 1998), substantiating the pervasive nature of this functional disconnection.

\section{Temporal Cortex/Hippocampus}

The medial temporal cortex has been the focus of a large number of investigations and findings of regional pathological changes in schizophrenia. Postmortem examination of the hippocampal formation has shown a number of abnormalities in schizophrenia, including reduced pyramidal cell size (Arnold et al, 1995; Benes et al, 1991; Zaidel et al, 1997) (but see Highley et al, 2003), reduced dendritic spine density (Rosoklija et al, 2000), reduced spinophilin mRNA expression (Law et al, 2004), reduced microtubule-associated proteins (Arnold et al, 1991), reduced BDNF (Durany et al, 2001), reduced mossy fiber terminal density (Kolomeets et al, 2007), reduced synaptic protein levels (Browning et al, 1993; Sawada et al, 2005; Young et al, 1998), alterations in NMDA receptor subtypes (reduced NR1 and increased NR2B) (Gao et al, 2000) and reduced non-NMDA ionotropic glutamate receptors (Harrison et al, 1991), as well as reduced mRNA expression of DISC1 binding partners (FEZ1, NUDEL, and LIS1) (Lipska et al, 2006b), among others.

Hippocampal volume reductions in schizophrenia have been shown by both voxel-based and ROI methodologies (Honea et al, 2005; Nelson et al, 1998; Weiss et al, 2005; Wright et al, 2000) are seen even when compared with patients' unaffected monozygotic twins, implicating nongenetic contributions to this finding (Suddath et al, 1990), and are present at the onset of psychosis (Bogerts et al, 1990). Furthermore, in patients, but not healthy individuals, hippocampal volume predicts the degree of prefrontal hypoactivation during the Wisconsin Card Sorting Test (Weinberger et al, 1992), leading to the hypothesis that fronto-limbic circuits may be particularly central to schizophrenia pathophysiology linked to cognitive dysfunction. Compelling rodent models have elaborated on this interaction: neonatal ventral hippocampal lesions in rodents disrupt medial temporal-prefrontal afferentation and produce numerous schizophrenia-like phenotypes after adolescence (Lipska and Weinberger, 2000) including working memory deficits (Lipska et al, 2002) and reduced prefrontal NAA (Bertolino et al, 2002), suggesting that, in fact, medial temporal lobe afferentation is critical to prefrontal cortical development and subsequent executive processing. Additionally, reductions in fractional anisotropy of temporal white matter, including the fornix (Fitzsimmons et al, 2009) and inferior longitudinal fasciculus (Ashtari et al, 2007), suggest compromised integrity of key bidirectional white matter tracts of the hippocampus, including those that communicate with the prefrontal cortex.

On the framework of these observations, recent functional imaging experiments have uncovered abnormalities of hippocampal-prefrontal interactions during executive tasks, particularly working memory, in schizophrenia. During the n-back working memory task, which is not thought to rely substantially on hippocampal processing, the hippocampus is deactivated and disengaged from prefrontal and inferior parietal regions (Meyer-Lindenberg et al, 2005b). However, patients with schizophrenia show impaired suppression of this region in the contexts of hypoactivated DLPFC (Meyer-Lindenberg et al, 2001), hyperactivated VLPFC (Thermenos et al, 2005), or hyperactivated basal ganglia (Kawasaki et al, 1992). Precise examination of hippocampal-DLPFC interactions during the 0 -back sensorimotor task in health and in schizophrenia shows an inverse correlation between these regions; however, in patients, but not healthy volunteers, this relationship remains inappropriately robust and regionally specific during the 2-back working memory condition (Meyer-Lindenberg et al, 2005b). As noted by MeyerLindenberg et al, impairment in modulating fronto-limbic circuitry in response to executive challenge could be predicted by an etiological model (Lipska et al, 2002) centered on early abnormal hippocampal physiology and connectivity resulting in subsequent retarded maturation of DLPFC and aberrant reciprocal innervation back to the hippocampus. Continued investigation of this hypothesis will require more direct studies of frontohippocampal circuitry during executive task challenge and will need to address other aspects of executive circuit abnormalities, including the role of medial temporal and prefrontal dopaminergic signaling (Aalto et al, 2005) in relation to basal ganglia function (Saunders et al, 1998).

\section{Basal Ganglia}

Postmortem examinations of the neostriatum implicating its involvement in schizophrenia have reported several 
findings, including: increased corticostriatal dendritic spine density (Kung et al, 1998; Roberts et al, 2005, 2008), reduced axonic mitochondria (Kung and Roberts, 1999), reduced GABA and glutamate uptake sites (Simpson et al, 1992), reduced cholinergic interneurons (Holt et al, 1999), increased dopamine concentrations (Mackay et al, 1982), and increased $\mathrm{D}_{2 / 3}$ and more robustly $\mathrm{D}_{4}$ receptors (Mackay et al, 1982; Murray et al, 1995; Seeman et al, 1993).

In vivo $\mathrm{PET}$ imaging studies have found upregulation of striatal $\mathrm{D}_{2}$ receptors as well, even in medication-naïve patients (Wong et al, 1986). Though there have been several negative studies, the weight of the literature supports an effect (Kestler et al, 2001; Laruelle, 1998). Striatal presynaptic dopamine synthesis and storage, measured by PET L-DOPA radiotracers, is increased in the schizophrenia prodrome (Howes et al, 2009) and in patients who fulfill full diagnostic criteria regardless of medication status (medicated, medication free, and neuroleptic naïve) (Hietala et al, 1995, 1999; Lindström et al, 1999; Mcgowan et al, 2004; Meyer-Lindenberg et al, 2002; Nozaki et al, 2009; Reith et al, 1994) (but see Dao-Castellana et al, 1997, showing only greater variability in patients and Elkashef et al, 2000 showing decreases in ventral striatum). Greater amphetamine-induced striatal dopamine release $\left(D_{2}\right.$ receptor radioligand displacement) in schizophrenia, measured by PET and SPECT, has also been well documented (Abi-Dargham et al, 1998; Breier et al, 1997; Laruelle et al, 1996). Taken together, these results establish abnormally heightened dopaminergic signaling in the striatum in schizophrenia.

As functional imaging studies have outlined a role for the striatum, and the caudate in particular, in spatial working memory (Postle and D'Esposito, 1999), planning (Owen et al, 1996), interference management (Vernaleken et al, 2007), and verbal working memory (Chang et al, 2007; Koch et al, 2008; Landau et al, 2009; Lewis et al, 2004; Rypma et al, 1999), striatal disinhibition may contribute to executive dysfunction in schizophrenia. This is in accord with the anatomy of basal ganglia-thalamo-cortical tracts, which features significant innervation of the above-discussed prefrontal regions (Middleton and Strick, 2002), and with the working memory deficits that arise from anterior neostriatal lesions in nonhuman primates, which can be remarkably similar to deficits seen with prefrontal lesions (Goldman and Rosvold, 1972). Conversely, striatal disinhibition in schizophrenia may be compensatory for or directly result from prefrontal dysfunction, as reciprocal corticostriatal modulation of the basal ganglia is also robust in the healthy individual. Bolstering prefrontal dopaminergic signaling with locally administered dopamine agonists results in reduced striatal dopamine release (Jaskiw et al, 1991; Kolachana et al, 1995). Likewise, frontal lesions result in exaggerated striatal dopamine release (Flores et al, 1996; Jaskiw et al, 1990a, b; Pycock et al, 1980), and surgical disconnection of frontostriatal circuitry impairs delayed alternation task performance in rats (Dunnett et al, 2005). Thus, to what degree abnormal neural activity in the striatum during executive functioning in schizophrenia is a primary or secondary phenomenon remains an unresolved question.

Nonetheless, hypothesizing that frontostriatal circuits are dominant (Pantelis et al, 1997) and specific (Badcock et al, 2005) contributors to schizophrenic cognitive impairments, a number of investigations have elucidated frontostriatal circuit abnormalities relevant to executive dysfunction in schizophrenia. Indirect evidence from functional imaging studies has been suggestive of striatal dysfunction (hyperactivation) in schizophrenia during inhibition tasks (Rubia et al, 2001), verbal fluency (Ragland et al, 2008), numeric working memory (Manoach et al, 2000), and the Wisconsin Card Sort Task (Kawasaki et al, 1992; Rubin et al, 1991, 1994). Perhaps the strongest evidence for the frontostriatal hypothesis comes from multimodal imaging approaches. Reduced DLPFC NAA shows an inverse relationship with amphetamine-induced striatal dopamine release, measured with $\left[{ }^{11} \mathrm{C}\right]$ raclopride PET, in patients with schizophrenia but not control subjects (Bertolino et al, 2000a). Though DLPFC NAA has been related to executive functioning in schizophrenia (Bertolino et al, 2000b), better characterization of striatal dysregulation and disturbed prefrontal physiology requires in vivo examination of both of these factors. This was recently achieved by Meyer-Lindenberg et al who studied schizophrenia patients and healthy volunteers with both $\left[{ }^{15} \mathrm{O}\right] \mathrm{H}_{2} \mathrm{O}$ PET during the Wisconsin Card Sorting Task and $\left[{ }^{18}\right.$ F]DOPA PET. Patients showed greater striatal presynaptic dopamine synthesis and storage and reduced prefrontal activation during the Card Sort compared with healthy individuals, and moreover, in patients these two abnormalities were highly correlated (MeyerLindenberg et al, 2002). These remarkable and predicted associations invite speculation that breakdowns in prefrontal neuronal integrity and function result in impaired restraint on striatal circuits, yielding an inflexible, dysregulated circuit. However, given the correlative nature of these findings, further testing is needed to establish causality.

\section{Thalamus}

As the thalamus is a central entry point for frontal cortexbound projections, including those from the striatum, there has been great interest in investigating this region for pathology in schizophrenia. Reductions in mediodorsal nucleus volume (Byne et al, 2002), neuronal number (Pakkenberg, 1990; Popken et al, 2000), and multiple ionotropic glutamatergic receptor types (NMDA, AMPA, Kainate) exist in thalamic nuclei (most prominently, mediodorsal and centromedial) of schizophrenia postmortem tissue (Ibrahim et al, 2000). Upregulation of exitatory amino-acid transporter (types 1 and 2) (Smith et al, 2001a) and vesicular glutamate transporter (Smith et al, 2001b) has also been reported in the same regions.

In vivo data showing illness-associated thalamic volume reductions (Andreasen et al, 1994a; Gur et al, 1998; Hulshoff Pol et al, 2001; Konick and Friedman, 2001) and reduced NAA measured by magnetic resonance techniques 
(Auer et al, 2001; Deicken et al, 2000; Ende et al, 2001) align well with reports of cellular neuropathological findings in the mediodorsal nuclei of schizophrenic patients. Reductions in $D_{2 / 3}$ receptor binding in the mediodorsal and pulvinar thalamic nuclei have also recently been documented (Buchsbaum et al, 2006; Talvik et al, 2003).

As thalamic activity is associated with the working memory (Callicott et al, 1999; Rypma et al, 1999), the Wisconsin Card Sorting Task (Goldberg et al, 1998), and the verbal fluency (Basho et al, 2007), pathological changes in this region in schizophrenia predict abnormal physiological responses to executive challenge. Indeed, hypoactivation of this region during working memory tasks (Andrews et al, 2006; Camchong et al, 2006; Mendrek et al, 2004; Schlösser et al, 2008) has been well replicated (though, see Manoach et al, 2000 showing hyperactivation). The mediodorsal nucleus of the thalamus shows reduced glucose metabolism in patients performing a modified California Verbal Learning Test (Hazlett et al, 2004) and manifests reduced connectivity with both regions in the DLPFC and medial temporal lobe (Mitelman et al, 2005). This agrees well with the possibility of structural derangement of prefrontal- and anterior cingulate-thalamic connections, as suggested by recent DTI studies using tractography (Kunimatsu et al, 2008) and fractional anisotropy measurements (Zou et al, 2008). In contrast, schizophrenia patients have shown increased thalamo-ventrolateral prefrontal and thalamodorsolateral prefrontal connectivity by structural equation modeling during an fMRI n-back paradigm (Schlösser et al, 2003). Though Schlosser and Mitelman used very different methodologies, it remains unclear how to reconcile their opposing results without additional experimentation.

\section{THE INFLUENCE OF SCHIZOPHRENIA RISK GENES ON EXECUTIVE CIRCUITRY}

As schizophrenia is highly heritable (Cardno and Gottesman, 2000), and healthy relatives of patients show executive task impairments and associated neuroimaging phenotypes, which are qualitatively similar to their affected family member but attenuated (Callicott et al, 2003a; Macdonald et al, 2008), and given a core role for executive dysfunction in schizophrenia, it is likely that functional variation in specific schizophrenia risk genes will impact aspects of the above-reviewed neurocircuit dynamics in predictable ways. Building on the endophenotype approach originally proposed by Gottesman and Sheilds (1972), recent advances in imaging genetics have begun to provide remarkably convergent evidence supporting this hypothesis, as delineated below (see Table 1). Such advances are crucial, in part, because among the multitude of molecular pathways impacting the interacting neural systems relevant to schizophrenia, any one candidate risk gene variant is likely to contribute only a nominal effect to the complex behavioral phenotype that establishes the clinical diagnosis, and the gene variants discussed here are no exception.
However, the experiments reviewed below have nonetheless been able to detect robust genetic effects by using neuroimaging techniques to assay 'intermediate' phenotypes at the neural systems level-a level of organization that is closer to the actual impact of a single gene variation-rather than measuring diagnosis itself (Mier et al, 2009). One particular strength of this approach is the ability to examine risk gene effects in healthy individuals that do not possess many of the confounds inherent in studying patients, such as medication exposure and psychotic symptoms, which has resulted in the majority of studies employing healthy populations; but by the same token, much work is still needed to better understand the effects of these genetic variants in the complex clinical and genetic context of schizophrenia.

\section{COMT}

Variation in the gene coding for catechol-O-methyltransferase $(C O M T)$, an enzyme central to cortical synaptic dopamine catabolism modestly influences risk of illness and has garnered significant attention for providing insight into the biological underpinnings of the imaging phenotype of schizophrenia. The rs4680 single nucleotide polymorphism (SNP) has been best studied, and the valine risk allele confers thermostability, permitting greater enzymatic activity and thereby reduced dopaminergic tone in cortical synapses. In a seminal paper by Egan et al and subsequent replications, the valine risk allele reliably predicts worse performance but increased dorsolateral prefrontal and anterior cingulate physiological response to the n-back task in both schizophrenic individuals and their unaffected siblings (Egan et al, 2001). This work has been extended to show that predicted prefrontal dopaminergic tone by combined genotype and pharmacological condition follow an inverted U-shaped response during working memory, such that risk allele homozygotes have improved and protective allele homozygotes have worse prefrontal efficiency in response to amphetamine (Mattay et al, 2003). Notably, functional variation in the COMT gene is not limited to the rs4680 SNP, but rather includes other polymorphisms, including a P2 promoter region SNP and a $3^{\prime}$ region SNP. These three SNPs show nonlinear interacting effects on prefrontal efficiency during working memory task performance, in agreement with predictions of resultant cortical dopaminergic catabolic rates, and highlight the complexity of genetic contributions to functional neuroimaging phenotypes, even within a single gene (Meyer-Lindenberg et al, 2006). To add to this complexity, the ability of COMT to regulate cortical dopamine relies on other genetically determined cellular resources, as suggested by studies of MTHFR by Roffman et al (2008). Variation in MTHFR (rs1801133), which also shows association with schizophrenia risk (Gilbody et al, 2007), regulates the availability of methyl groups for use by COMT and, in combination with rs4680, predicts DLPFC activation during working memory in a manner consistent with the 
Table 1 Selected Executive Function Circuit Findings in Schizophrenia

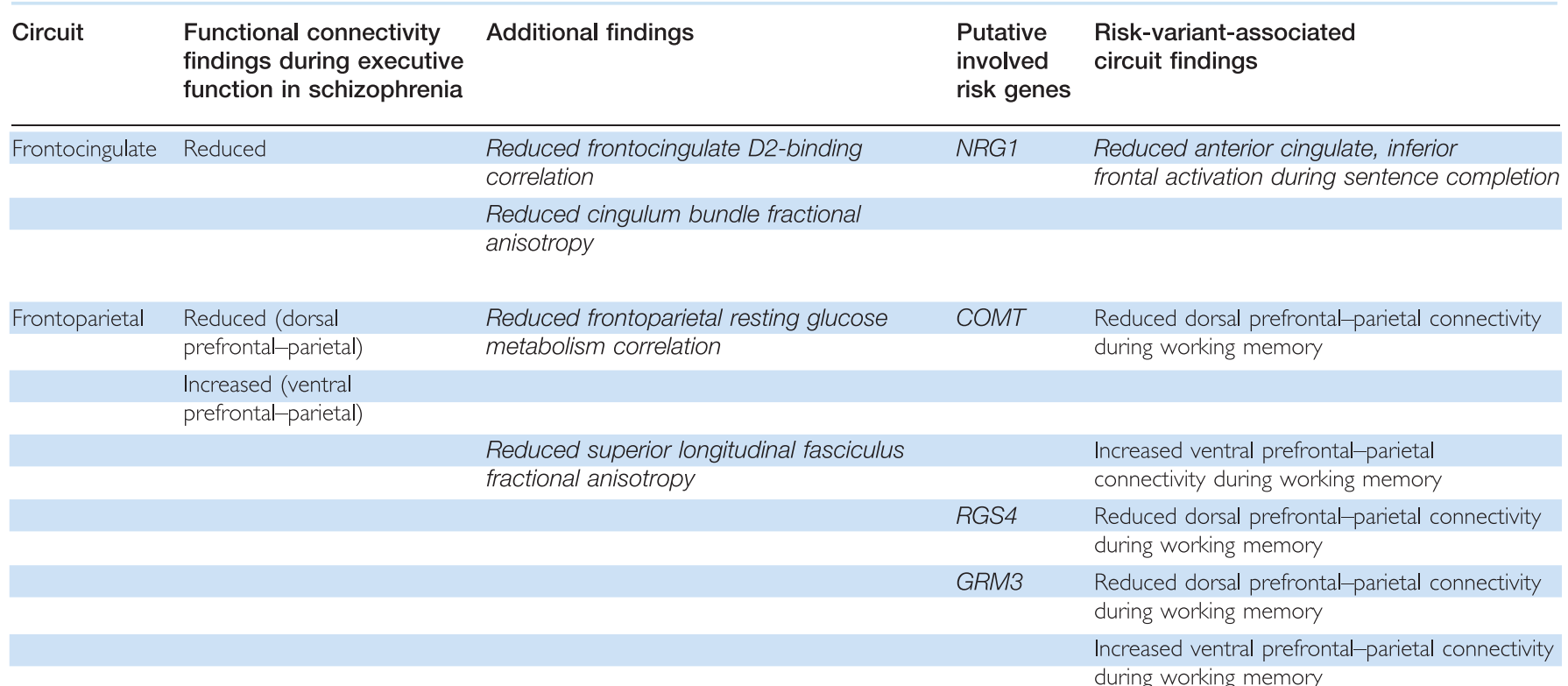

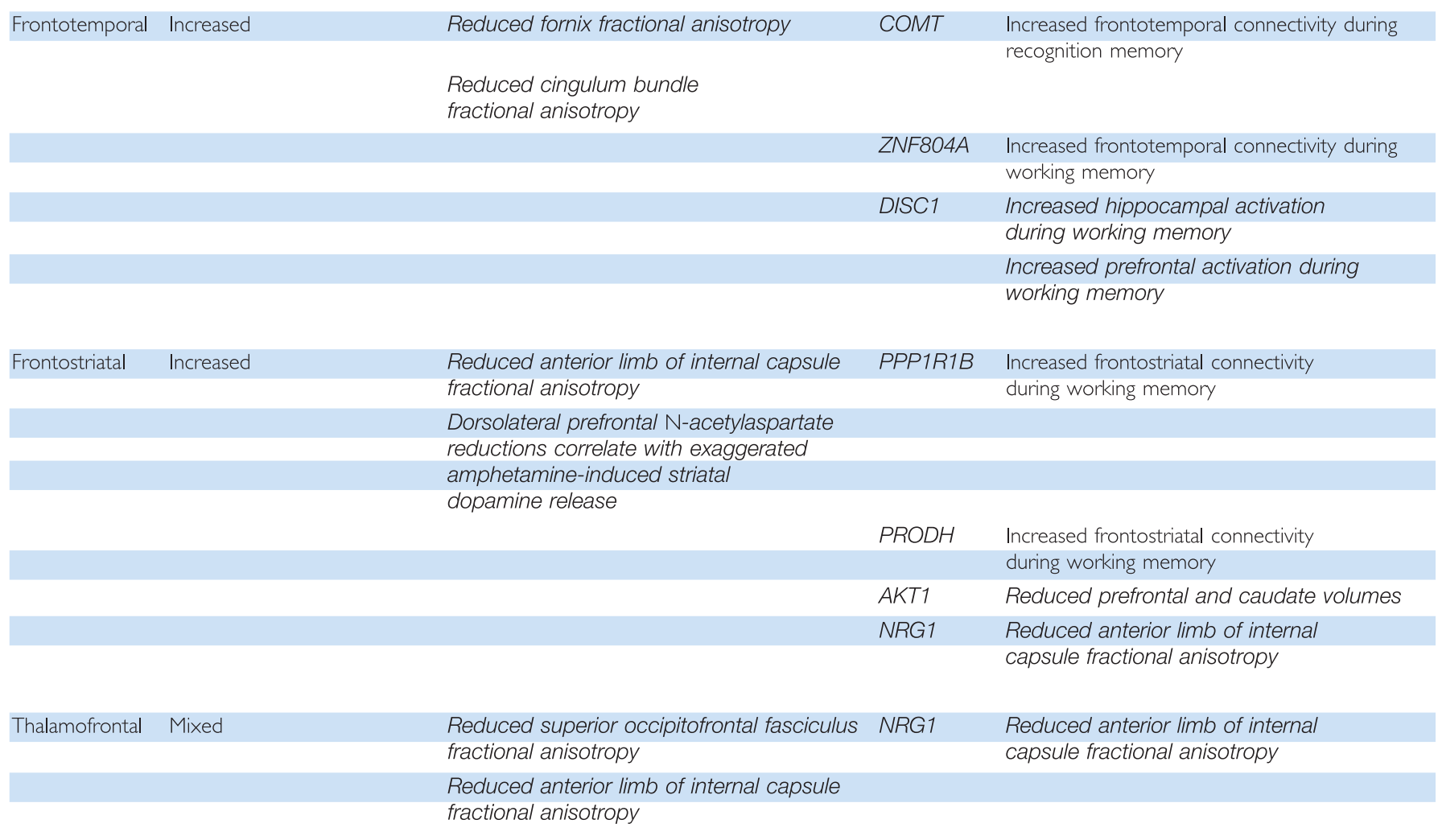

Italicized findings indicate indirect evidence (ie, not executive functional connectivity data)

above-mentioned inverted U-shaped curve. Taken together, these data provide further support for the proposition that suboptimal prefrontal dopamine signaling contributes to the prefrontal imaging phenotypes of executive dysfunction in schizophrenia.

Importantly, recent investigations have expanded this line of inquiry to assess the impact of genetically defined cortical dopamine tone on distributed circuitry relevant to executive function, and a number of results have emerged that are consistent with the data and putative mechanisms regarding schizophrenia itself, reviewed above. For instance, during the n-back working memory task, valine carriers show increased ventrolateral relative to dorsolateral prefrontal engagement and increased ventrolateral relative to 
dorsolateral connectivity with parietal regions, as had been seen in schizophrenia earlier (Tan et al, 2007). Additionally, just as inappropriate prefrontal-hippocampal coupling persists during working memory in schizophrenia patients (Meyer-Lindenberg et al, 2005b), during a recognition memory task that activates the hippocampus, carriers of COMT rs4680 valine alleles show disadvantageous increased prefrontal-hippocampal connectivity (Bertolino et al, 2006). Finally, in agreement with the above-highlighted frontostriatal circuit abnormalities in schizophrenia, particularly disinhibited presynaptic striatal dopaminergic signaling in association with DLPFC hypofunction, postmortem data show that COMT valine alleles predict increased tyrosine hydroxylase mRNA expression in the midbrain (Akil et al, 2003), origin of dopaminergic projections to the striatum. Corroborating this effect are in vivo data describing COMT genotype effects on the relationship between midbrain dopamine storage and prefrontal activation during the n-back task: in met homozygotes, this relationship was negative, but in val carriers, it was positive (MeyerLindenberg et al, 2005a). This has been interpreted as a downstream effect of genetically conferred variation of prefrontal dopaminergic neurotransmission, as midbrain relative to cortical COMT expression is weak (Kastner et al, 1994), such that suboptimal prefrontal output to mesencephalic inhibitory cells results in exaggerated activity of dopamine neurons projecting to the striatum.

\section{RGS4}

RGS4 is an important modulator of central dopamine, glutamate, and neuregulin G-protein receptor systems, and transcript expression in the DLPFC of schizophrenia patients has been shown to be reduced (Mirnics et al, 2001). An SNP ( $r s 951436 \mathrm{C} \rightarrow \mathrm{A}$ ) in the gene coding for this protein is associated with both schizophrenia (Chowdari et al, 2002) and reductions in DLPFC volumes (Prasad et al, 2005). Buckholtz et al $(2007 \mathrm{a}, \mathrm{b})$ studied this risk SNP in a large group of healthy individuals undergoing functional MRI scans during the n-back task and found that individuals carrying more risk alleles evidenced greater activation in the left ventrolateral PFC, but less activation in the right lateral PFC, temporal cortex, and caudate (Buckholtz et al, 2007a). Similar to investigations in COMT (Tan et al, 2007) and schizophrenia itself (Tan et al, 2006), examination of functional connectivity between these differentially activated nodes showed that risk alleles impaired cooperativity between right hemispheric nodes activated by the task (eg, DLPFC, PPC) but exaggerated cooperativity between VLPFC and nodes deactivated by task (eg, mPFC, superior temporal cortex, posterior cingulate, and parahippocampal gyrus) (Buckholtz et al, 2007a). Notably, when regional brain activations during the n-back task are examined with consideration of both COMT and RGS4 genotypes, there exists an epistatic interaction, such that RGS4 risk allele-associated greater DLPFC and midbrain activation occurs only in the context of COMT risk allele carriers (Buckholtz et al, 2007b). Regardless of whether this interaction occurs biologically at the molecular (eg, COMT regulating RGS4 gene expression, Lipska et al, 2006a) or systems level (eg, inefficient executive circuits being more susceptible to RGS4 effects) (Buckholtz et al, 2007b), these data highlight the complex contribution of schizophrenia risk gene networks to executive processing.

\section{GRM3}

An SNP in the gene coding for the metabotropic type II glutamate receptor mGluR3, GRM3 (rs6465084), results in weakly increased risk for schizophrenia, reduced prefrontal excitatory amino-acid transporter 2 mRNA expression (EEAT2), worse verbal fluency performance, and reduced DLPFC neuronal integrity as measured by magnetic resonance spectroscopy (Egan et al, 2004; Marenco et al, 2006). As in COMT, during the n-back working memory task, greater DLPFC BOLD signal activation for the same performance level ('prefrontal inefficiency') is seen in carriers of the risk SNP (Egan et al, 2004). However, this finding of GRM3 risk allele-associated prefrontal inefficiency during working memory, as in RGS4, has been replicated in COMT rs4680 risk allele carriers but not in methionine homozygotes, suggesting an epistatic interaction between these two risk genes. Furthermore, carriers of both COMT and GRM3 risk alleles show disproportionately greater VLPFC over DLPFC connectivity with parietal regions activated by this task (Tan et al, 2007), similar to the schizophrenia phenotype (Tan et al, 2006).

\section{PPP1R1B}

Dopamine- and cAMP-regulated phosphoprotein of molecular weight $32 \mathrm{kDa}$ (DARPP-32) is abundant in the striatum and has a key function in modulating dopaminergic postsynaptic intracellular signaling through multifaceted effects on protein kinases (Svenningsson et al, 2004). One common haplotype in the $P P P 1 R 1 B$ gene coding for DARPP-32 shows an association with schizophrenia, with worse IQ, verbal fluency, working memory, and Wisconsin Card Sorting performance, with reduced striatal volumes, with reduced striatal BOLD activation during the n-back, and with increased frontostriatal connectivity. Notably, both the activation and connectivity findings were replicated in a separate cohort during performance of an emotional face-matching task (Meyer-Lindenberg et al, 2007).

\section{PRODH}

A functional haplotype (rs4819756 and rs2870983 and rs450046 minor alleles) in the proline oxydase gene, $P R O D H$, shows increased enzymatic activity, risk for schizophrenia, diminished striatal volumes, reduced striatal BOLD activation, and increased frontostriatal connectivity during the n-back task (Kempf et al, 2008). Despite 
significant differences between the functions of proline oxydase and DARPP-32, these results are remarkably similar to those of $P P P 1 R 1 B$ and converge on circuitry (prefrontal-neostriatal) that is dysregulated in schizophrenia (Meyer-Lindenberg et al, 2002).

\section{AKT-1}

AKT-1 is an intracellular signaling protein that has an important function in dopamine-mediated neurotransmission (Beaulieu et al, 2005; Wei et al, 2007) and has shown reduced expression in schizophrenic brains (Emamian et al, 2004) and lymphocytes (Tan et al, 2008). Further, several reports have found an association between a functional $A K T-1$ genetic variations and schizophrenia (Emamian et al, 2004; Tan et al, 2008). One such variation, an SNP, rs1130233, additionally shows a relationship with neuropsychological assessments of executive function as well as n-back-related prefrontal activation. The risk allele also imparts reduced prefrontal and caudate volumes, in agreement with its hypothesized impact on frontostriatal circuitry, though formal testing of functional connectivity has not been performed at this date (Tan et al, 2008).

\section{DISC-1}

The disrupted in schizophrenia (DISC-1) gene codes for a protein abundant in the hippocampus, which partners with Nudel and other dynein complex proteins to impact centrosomal function, neurite outgrowth, and neuronal migration (Kamiya et al, 2005). Variations in DISC-1 are associated with schizophrenia (Callicott et al, 2005; Ekelund et al, 2004; Hennah et al, 2003; Hodgkinson et al, 2004), and recent multimodal imaging data have evidenced an effect of the DISC-1 Ser704Cys polymorphism on hippocampal structure and function in healthy adults (Callicott et al, 2005). Specifically, serine homozygotes showed reduced hippocampal gray matter volume, lower hippocampal $\mathrm{N}$ acetyl aspartate, and during the n-back working memory task, abnormally greater hippocampal activation (Callicott et al, 2005). These results align well with the impaired suppression of medial temporal lobe activity during executive processing seen in schizophrenia (Meyer-Lindenberg et al, 2001). Furthermore, during verbal fluency task performance, serine homozygotes show increased prefrontal activation (Prata et al, 2008), though to what degree frontotemporal connectivity is directly influenced by this polymorphism remains to be tested.

\section{ZNF804A}

In a recent genome-wide association study, an SNP (rs1344706) in ZNF804A, a gene coding for a protein of unclear function but potential gene regulatory ability, showed independent, significant association with schizophrenia (O'Donovan et al, 2008). Comparing healthy individuals with either no, one, or two risk alleles, Esslinger et al (2009) have found that the number of risk alleles predicted greater prefrontal-hippocampal functional connectivity during the n-back working memory task, just as had been described earlier in patients (Meyer-Lindenberg et al, 2005b), reinforcing the fact that greater functional connectivity (especially with a dysfunctional prefrontal cortex, as in schizophrenia), not only less, can be the risk phenotype. Better understanding of the biology of ZNF804A is needed to clarify the nature of this observation, but it is nonetheless remarkable that a risk gene without a priori evidence for either prefrontal or hippocampal involvement can so clearly show a predicted illness circuit phenotype in this way.

\section{NRG-1}

Neuregulin1 (NRG-1) isoforms and its receptor ErbB4 have important functions in potentially illness-relevant neural processes, including neuronal migration, axonal guidance and myelination, synaptic plasticity, and glutamatergic dendritic spine maturation (Barros et al, 2009; Mei and Xiong, 2008). Variation in the $N R G-1$ gene has shown association with schizophrenia diagnosis, behavioral abnormalities in mouse models responsive to antipsychotic medication (Li et al, 2006; Stefansson et al, 2002), and altered neuregulin isoform expression (Law et al, 2006).

In a group of individuals at high risk of developing schizophrenia by virtue of strong family history, carrier status of an NRG1 risk allele (SNP8NRG243177 polymorphism, which influences neuregulin transcript expression, Law et al, 2006) predicted development of psychotic symptoms as well as reduced activation in medial prefrontal and temporo-occipital regions during a sentence completion task (Hall et al, 2006).

The number of NRG-1 risk alleles carried in healthy adults correlates with reduced semantic verbal fluency performance and reduced anterior cingulate, inferior frontal, and middle temporal activation measured by fMRI BOLD signal (Kircher et al, 2009). Disrupted microstructural connectivity in association with the risk allele of this same polymorphism is evidence by reduced white matter density and fractional anisotropy in the anterior limb of the internal capsule (Mcintosh et al, 2007), which contains important axonal fibers linking the prefrontal cortex with other nodes in the extended executive network. Future work is needed to confirm these findings and determine to what degree these abnormalities explain functional differences in individuals with different allelic risk loads.

\section{SUMMARY AND FUTURE DIRECTIONS}

Key brain regions that show postmortem and in vivo evidence for disarray in schizophrenia are important in executive functioning, and are physiologically abnormal during executive challenge in patients, evidence characteristically aberrant interactions and remarkable susceptibility to variation in putative schizophrenia risk genes. 
DLPFC dysfunction and aberrant functional connectivity, relatively increased VLPFC involvement in executive circuitry, ACC, and IPL dysfunction and reduced coupling with DLPFC, impairment in suppression of medial temporal activity during certain executive challenges, prefrontal disinhibition of mesostriatal dopaminergic signaling, and reduced thalamofrontal cooperativity not only form a complex landscape of circuit changes in schizophrenia, but also, in selected subsets of these, create quantifiable links to emerging molecular footprints of genetic predisposition to psychosis. Systematic work is needed to better characterize the dynamics of these systems-level abnormalities in response to particular executive task demands, pharmacological interventions, and genetic environments.

Specifically, several avenues of research promise to provide invaluable insights into pathophysiology and ultimately targeted treatment of this devastating illness.

To address accumulating evidence of genetic heterogeneity underlying the disorder and concomitant variability in psychopathological and neuropsychological profiles, all of which may have contributed to apparent inconsistencies in the literature, more extensive genetically, clinically, and cognitively stratified studies are necessary. Likewise, longitudinal studies directed at understanding both naturalistic and pharmacologically induced fluctuations in executive network function are essential to assess the stability of circuit perturbations in schizophrenia over the course of illness and treatment. Additionally, developing advanced methodologies to bridge molecular and physiological data and fuel both candidate risk gene discovery and biological validation has become increasingly important. One such approach is to use neurocircuit risk phenotypes as quantitative trait variables to identify genetic factors contributing to executive dysfunction in psychotic disorders. Potkin et al (2008) have begun to implement this strategy with DLPFC activation alone as the quantitative trait variable, yielding novel results. As efforts to characterize and quantify the above-outlined systems-level circuitry disruptions in schizophrenia advance, bringing greater predictive power for diagnosis and treatment response to nuanced functional imaging phenotypes, this reverse mapping - from imaging to genes - may become increasingly valuable for understanding illness pathophysiology and for developing pharmacogenetic models. Similarly, development of robust data-driven analytical techniques, such as parallel independent components analysis (Liu et al, 2009) to meaningfully combine highly dimensional genetic and imaging datasets in a coordinated and comprehensive fashion may eventually help shed light on the underlying structures of each. Finally, because inherited variation in DNA sequences, though incredibly useful for identifying key molecular pathways to schizophrenia as illustrated above, is likely only a partial contributor to illness brain phenotypes, it will be progressively more important to explore connections between executive circuit dynamics and de novo mutations (Stefansson et al, 2008), epigenetics
(Huang and Akbarian, 2007), and gene-environment interactions (Caspi et al, 2005; Nicodemus et al, 2008) associated with schizophrenia.

In summary, schizophrenia patients show a remarkable number of characteristic abnormalities of executive circuitry, evident in vivo with functional neuroimaging techniques, the topography of which corresponds well to other pathological findings in postmortem tissue and in vivo neurochemical (magnetic resonance spectroscopy, neuroreceptor mapping) assays. A growing list of candidate schizophrenia risk genes show variation in executive circuit dynamics, akin to that in illness, suggesting that increasing attention to genetic and genetic-environmental interactions yields promise for better understanding the biology of executive dysfunction in schizophrenia.

\section{ACKNOWLEDGEMENTS}

This work was supported by the National Institute of Mental Health Intramural Research Program.

\section{DISCLOSURE}

The authors declared no conflict of interest.

\section{REFERENCES}

Aalto S, Bruck A, Laine M, Nagren K, Rinne JO (2005). Frontal and temporal dopamine release during working memory and attention tasks in healthy humans: a positron emission tomography study using the high-affinity dopamine d2 receptor ligand [11c]flb 457. J Neurosci 25: 2471-2477.

Abbott C, Bustillo J (2006). What have we learned from proton magnetic resonance spectroscopy about schizophrenia? A critical update. Curr Opin Psychiatry 19: 135-139.

Abi-Dargham A, Gil R, Krystal J, Baldwin RM, Seibyl JP, Bowers M et al (1998). Increased striatal dopamine transmission in schizophrenia: confirmation in a second cohort. Am J Psychiatry 155: 761-767.

Abi-Dargham A, Mawlawi O, Lombardo I, Gil R, Martinez D, Huang Y et al (2002). Prefrontal dopamine d1 receptors and working memory in schizophrenia. $J$ Neurosci 22: 3708-3719. Evidence of upregulated D1 receptors in the DLPFC in schizophrenia, potentially in response to reduced dopaminergic input previously shown

Akbarian S, Kim JJ, Potkin SG, Hagman JO, Tafazzoli A, Bunney Jr WE et al (1995). Gene expression for glutamic acid decarboxylase is reduced without loss of neurons in prefrontal cortex of schizophrenics. Arch Gen Psychiatry 52: 258266

Akbarian S, Sucher N, Bradley D, Tafazzoli A, Trinh D, Hetrick W et al (1996). Selective alterations in gene expression for $n$ mda receptor subunits in prefrontal cortex of schizophrenics. J Neurosci 16: 19-30.

Akil M, Kolachana BS, Rothmond DA, Hyde TM, Weinberger DR, Kleinman JE (2003). Catechol-o-methyltransferase genotype and dopamine regulation in the human brain. J Neurosci 23: 2008-2013.

Akil M, Pierri JN, Whitehead RE, Edgar CL, Mohila C, Sampson AR et al (1999). Lamina-specific alterations in the dopamine innervation of the prefrontal cortex in schizophrenic subjects. Am J Psychiatry 156: 1580-1589.

Albert KA, Hemmings Jr HC, Adamo AIB, Potkin SG, Akbarian S, Sandman CA et al (2002). Evidence for decreased darpp-32 in the prefrontal cortex of patients with schizophrenia. Arch Gen Psychiatry 59: 705-712. Demonstration of abnormal DARPP-32 concentrations in the schizophrenic DLPFC, in line with prefrontal imaging genetics results.

Andreasen NC, Arndt S, Swayze V, Cizadlo T, Flaum M, O'Leary D et al (1994a). Thalamic abnormalities in schizophrenia visualized through magnetic resonance image averaging. Science 266: 294-298. First significant investigation of thalamic size by MRI technology, fueling subsequent experiments on sensory-gating abnormalities in schizophrenia. 
Andreasen NC, Flashman L, Flaum M, Arndt S, Swayze 2nd V, O'Leary DS et al (1994b). Regional brain abnormalities in schizophrenia measured with magnetic resonance imaging. JAMA 272: 1763-1769.

Andreasen NC, Rezai K, Alliger R, Swayze II WW, Flaum M, Kirchner P et al (1992). Hypofrontality in neuroleptic-naive patients and in patients with chronic schizophrenia: assessment with xenon 133 single-photon emission computed tomography and the tower of london. Arch Gen Psychiatry 49: 943-958.

Andrews J, Wang L, Csernansky JG, Gado MH, Barch DM (2006). Abnormalities of thalamic activation and cognition in schizophrenia. Am J Psychiatry 163: 463-469.

Arnold SE, Franz BR, Gur RC, Gur RE, Shapiro RM, Moberg PJ et al (1995). Smaller neuron size in schizophrenia in hippocampal subfields that mediate corticalhippocampal interactions. Am J Psychiatry 152: 738-748.

Arnold SE, Lee VM, Gur RE, Trojanowski JQ (1991). Abnormal expression of two microtubule-associated proteins (map2 and map5) in specific subfields of the hippocampal formation in schizophrenia. Proc Natl Acad Sci USA 88: 10850-10854.

Ashtari M, Cottone J, Ardekani BA, Cervellione K, Szeszko PR, Wu J et al (2007). Disruption of white matter integrity in the inferior longitudinal fasciculus in adolescents with schizophrenia as revealed by fiber tractography. Arch Gen Psychiatry 64: 1270-1280.

Auer DP, Wilke M, Grabner A, Heidenreich JO, Bronisch T, Wetter TC (2001). Reduced naa in the thalamus and altered membrane and glial metabolism in schizophrenic patients detected by $1 \mathrm{~h}-\mathrm{mrs}$ and tissue segmentation. Schizophr Res 52: 87-99.

Badcock JC, Michie PT, Rock D (2005). Spatial working memory and planning ability: contrasts between schizophrenia and bipolar i disorder. Cortex 41 753-763.

Baiano M, David A, Versace A, Churchill R, Balestrieri M, Brambilla P (2007). Anterior cingulate volumes in schizophrenia: a systematic review and a metaanalysis of mri studies. Schizophr Res 93: 1-12.

Barbalat G, Chambon V, Franck N, Koechlin E, Farrer C (2009). Organization of cognitive control within the lateral prefrontal cortex in schizophrenia. Arch Gen Psychiatry 66: 377-386.

Barch DM, Carter CS, Braver TS, Sabb FW, MacDonald III A, Noll DC et al (2001). Selective deficits in prefrontal cortex function in medication-naive patients with schizophrenia. Arch Gen Psychiatry 58: 280-288.

Barch DM, Csernansky JG (2007). Abnormal parietal cortex activation during working memory in schizophrenia: verbal phonological coding disturbances versus domain-general executive dysfunction. Am J Psychiatry 164: 1090-1098.

Barch DM, Sheline YI, Csernansky JG, Snyder AZ (2003). Working memory and prefrontal cortex dysfunction: specificity to schizophrenia compared with major depression. Biol Psychiatry 53: 376-384.

Barros CS, Calabrese B, Chamero P, Roberts AJ, Korzus E, Lloyd K et al (2009). Impaired maturation of dendritic spines without disorganization of cortical cell layers in mice lacking nrg1/erbb signaling in the central nervous system. Proc Natl Acad Sci 106: 4507-4512.

Basho S, Palmer ED, Rubio MA, Wulfeck B, Müller R-A (2007). Effects of generation mode in fmri adaptations of semantic fluency: paced production and overt speech. Neuropsychologia 45: 1697-1706.

Bassett DS, Bullmore E, Verchinski BA, Mattay VS, Weinberger DR, MeyerLindenberg A (2008). Hierarchical organization of human cortical networks in health and schizophrenia. J Neurosci 28: 9239-9248. Support for distributed neural network disturbances in schizophrenia using novel, comprehensive methodologies.

Beasley CL, Zhang ZJ, Patten I, Reynolds GP (2002). Selective deficits in prefrontal cortical gabaergic neurons in schizophrenia defined by the presence of calciumbinding proteins. Biol Psychiatry 52: 708-715.

Beaulieu J-M, Sotnikova TD, Marion S, Lefkowitz RJ, Gainetdinov RR, Caron MG (2005). An akt/[beta]-arrestin 2/pp2a signaling complex mediates dopaminergic neurotransmission and behavior. Cell 122: 261-273.

Becker TM, Kerns JG, MacDonald III AW, Carter CS (2008). Prefrontal dysfunction in first-degree relatives of schizophrenia patients during a stroop task. Neuropsychopharmacology 33: 2619-2625.

Benes F, Vincent S, Alsterberg G, Bird E, SanGiovanni J (1992a). Increased gabaa receptor binding in superficial layers of cingulate cortex in schizophrenics. J Neurosci 12: 924-929.

Benes FM, Sorensen I, Bird ED (1991). Reduced neuronal size in posterior hippocampus of schizophrenic patients. Schizophr Bull 17: 597-608.

Benes FM, Sorensen I, Vincent SL, Bird ED, Sathi M (1992b). Increased density of glutamate-immunoreactive vertical processes in superficial laminae in cingulate cortex of schizophrenic brain. Cereb Cortex 2: 503-512.

Benes FM, Vincent SL, Todtenkopf M (2001). The density of pyramidal and nonpyramidal neurons in anterior cingulate cortex of schizophrenic and bipolar subjects. Biol Psychiatry 50: 395-406.
Berman K, Doran A, Pickar D, Weinberger D (1993). Is the mechanism of prefrontal hypofunction in depression the same as in schizophrenia? Regional cerebral blood flow during cognitive activation. Br J Psychiatry 162: 183-192. First evidence for diagnostic specificity of prefrontal hypofunction in schizophrenia.

Berman KF, Illowsky BP, Weinberger DR (1988). Physiological dysfunction of dorsolateral prefrontal cortex in schizophrenia: IV. Further evidence for regional and behavioral specificity. Arch Gen Psychiatry 45: 616-622. First demonstration of task specificity of prefrontal hypofunction in schizophrenia.

Berman KF, Ostrem JL, Randolph C, Gold J, Goldberg TE, Coppola R et al (1995). Physiological activation of a cortical network during performance of the wisconsin card sorting test: a positron emission tomography study. Neuropsychologia 33: 1027-1046.

Berman KF, Torrey EF, Daniel DG, Weinberger DR (1992). Regional cerebral blood flow in monozygotic twins discordant and concordant for schizophrenia. Arch Gen Psychiatry 49: 927-934. Discrimination of non-genetic contribution to hypofrontal phenotype in schizophrenia via twin studies.

Berman KF, Zec RF, Weinberger DR (1986). Physiologic dysfunction of dorsolateral prefrontal cortex in schizophrenia: li. Role of neuroleptic treatment, attention, and mental effort. Arch Gen Psychiatry 43: 126-135.

Bertolino A, Breier A, Callicott JH, Adler C, Mattay VS, Shapiro M et al (2000a). The relationship between dorsolateral prefrontal neuronal $n$-acetylaspartate and evoked release of striatal dopamine in schizophrenia. Neuropsychopharmacology 22: 125-132. First demonstration that neuronal integrity of DLPFC is associated with exaggerated striatal dopaminergic neurotransmission

Bertolino A, Esposito G, Callicott JH, Mattay VS, Van Horn JD, Frank JA et al (2000b). Specific relationship between prefrontal neuronal $n$-acetylaspartate and activation of the working memory cortical network in schizophrenia. Am J Psychiatry 157: 26-33. First demonstration that neuronal integrity, as measured by NAA, of DLPFC is associated with its function during working memory.

Bertolino A, Roffman JL, Lipska BK, van Gelderen P, Olson A, Weinberger DR (2002). Reduced n-acetylaspartate in prefrontal cortex of adult rats with neonatal hippocampal damage. Cereb Cortex 12: 983-990.

Bertolino A, Rubino V, Sambataro F, Blasi G, Latorre V, Fazio L et al (2006). Prefrontal-hippocampal coupling during memory processing is modulated by comt val158met genotype. Biol Psychiatry 60: 1250-1258.

Bogerts B, Ashtari M, Degreef G, Alvir JMJ, Bilder RM, Lieberman JA (1990). Reduced temporal limbic structure volumes on magnetic resonance images in first episode schizophrenia. Psychiatry Res 35: 1-13.

Boksman K, Théberge J, Williamson P, Drost DJ, Malla A, Densmore M et al (2005). A 4.0-t fmri study of brain connectivity during word fluency in first-episode schizophrenia. Schizophr Res 75: 247-263.

Bozikas VP, Kosmidis MH, Kiosseoglou G, Karavatos A (2006). Neuropsychological profile of cognitively impaired patients with schizophrenia. Compr Psychiatry 47: 136-143.

Breier A, Su T-P, Saunders R, Carson RE, Kolachana BS, de Bartolomeis A et al (1997). Schizophrenia is associated with elevated amphetamine-induced synaptic dopamine concentrations: evidence from a novel positron emission tomography method. Proc Natl Acad Sci USA 94: 2569-2574. First use of raclopride $\mathrm{PET}$ technique to demonstrate exaggerated striatal dopamine release in schizophrenia in response to amphetamine challenge.

Broome MR, Matthiasson P, Fusar-Poli P, Woolley JB, Johns LC, Tabraham P et al (2009). Neural correlates of executive function and working memory in the 'at-risk mental state'. BrJ Psychiatry 194: 25-33.

Browning MD, Dudek EM, Rapier JL, Leonard S, Freedman R (1993). Significant reductions in synapsin but not synaptophysin specific activity in the brains of some schizophrenics. Biol Psychiatry 34: 529-535.

Buchanan RW, Francis A, Arango C, Miller K, Lefkowitz DM, McMahon RP et al (2004). Morphometric assessment of the heteromodal association cortex in schizophrenia. Am J Psychiatry 161: 322-331.

Buchsbaum BR, Greer S, Chang W-L, Berman KF (2005). Meta-analysis of neuroimaging studies of the wisconsin card-sorting task and component processes. Hum Brain Mapp 25: 35-45.

Buchsbaum MS, Christian BT, Lehrer DS, Narayanan TK, Shi B, Mantil J et al (2006). D2/d3 dopamine receptor binding with [f-18]fallypride in thalamus and cortex of patients with schizophrenia. Schizophr Res 85: 232-244.

Buckholtz JW, Meyer-Lindenberg A, Honea RA, Straub RE, Pezawas L, Egan MF et al (2007a). Allelic variation in rgs4 impacts functional and structural connectivity in the human brain. J Neurosci 27: 1584-1593. First report to show association between RGS4 and imaging schizophrenia phenotypes.

Buckholtz JW, Sust S, Tan HY, Mattay VS, Straub RE, Meyer-Lindenberg A et al (2007b). Fmri evidence for functional epistasis between comt and rgs4. Mol Psychiatry 12: 893-895. 
Byne W, Buchsbaum MS, Mattiace LA, Hazlett EA, Kemether E, Elhakem SL et al (2002). Postmortem assessment of thalamic nuclear volumes in subjects with schizophrenia. Am J Psychiatry 159: 59-65.

Callicott JH, Egan MF, Mattay VS, Bertolino A, Bone AD, Verchinksi B et al (2003a). Abnormal fmri response of the dorsolateral prefrontal cortex in cognitively intact siblings of patients with schizophrenia. Am J Psychiatry 160: 709-719.

Callicott JH, Mattay VS, Bertolino A, Finn K, Coppola R, Frank JA et al (1999). Physiological characteristics of capacity constraints in working memory as revealed by functional mri. Cereb Cortex 9: 20-26.

Callicott JH, Mattay VS, Verchinski BA, Marenco S, Egan MF, Weinberger DR (2003b). Complexity of prefrontal cortical dysfunction in schizophrenia: more than up or down. Am J Psychiatry 160: 2209-2215. Influential paper introducing the concept of prefrontal inefficiency in schizophrenia subjects performing the n-back at near-normal performance in contrast to hypofrontality in lower scoring subjects.

Callicott JH, Ramsey NF, Tallent K, Bertolino A, Knable MB, Coppola R et al (1998). Functional magnetic resonance imaging brain mapping in psychiatry: methodological issues illustrated in a study of working memory in schizophrenia. Neuropsychopharmacology 18: 186-196.

Callicott JH, Straub RE, Pezawas L, Egan MF, Mattay VS, Hariri AR et al (2005). Variation in disc1 affects hippocampal structure and function and increases risk for schizophrenia. Proc Natl Acad Sci USA 102: 8627-8632. First demonstration of influence of DISC1 risk allele carrier status on schizophrenia imaging phenotypes of the medial temporal lobe.

Camchong J, Dyckman KA, Chapman CE, Yanasak NE, McDowell JE (2006). Basal ganglia-thalamocortical circuitry disruptions in schizophrenia during delayed response tasks. Biol Psychiatry 60: 235-241.

Cannon TD, Glahn DC, Kim J, Van Erp TGM, Karlsgodt K, Cohen MS et al (2005). Dorsolateral prefrontal cortex activity during maintenance and manipulation of information in working memory in patients with schizophrenia. Arch Gen Psychiatry 62: 1071-1080.

Cannon TD, Thompson PM, van Erp TGM, Toga AW, Poutanen V-P, Huttunen M et al (2002). Cortex mapping reveals regionally specific patterns of genetic and disease-specific gray-matter deficits in twins discordant for schizophrenia. Proc Natl Acad Sci USA 99: 3228-3233. Twin study clarifying genetic and diseaserelated alterations in DLPFC gray matter concentrations.

Cantor-Graae E, Warkentin S, Franzen G, Risberg J, Ingvar DH (1991). Aspects of stability of regional cerebral blood flow in chronic schizophrenia: an 18-year followup study. Psychiatry Res 40: 253-266. Only study to document stability of hypofrontality over many years time.

Cardno AG, Gottesman (2000). Twin studies of schizophrenia: from bow-and-arrow concordances to star wars mx and functional genomics. Am J Med Genet 97: $12-17$

Carter CS, MacDonald III AW, Ross LL, Stenger VA (2001). Anterior cingulate cortex activity and impaired self-monitoring of performance in patients with schizophrenia: an event-related fmri study. Am J Psychiatry 158: 1423-1428.

Carter CS, Mintun M, Nichols T, Cohen JD (1997). Anterior cingulate gyrus dysfunction and selective attention deficits in schizophrenia: [150]h2o pet study during single-trial stroop task performance. Am J Psychiatry 154: 1670-1675.

Carter CS, Perlstein W, Ganguli R, Brar J, Mintun M, Cohen JD (1998). Functional hypofrontality and working memory dysfunction in schizophrenia. Am J Psychiatry 155: 1285-1287.

Caspi A, Moffitt TE, Cannon M, McClay J, Murray R, Harrington H et al (2005). Moderation of the effect of adolescent-onset cannabis use on adult psychosis by a functional polymorphism in the catechol-o-methyltransferase gene: Iongitudinal evidence of a gene $x$ environment interaction. Biol Psychiatry 57: 1117-1127. Evidence for gene-environment interactions predisposing to schizophrenia.

Catafau AM, Parellada E, Lomena FJ, Bernardo M, Pavia J, Ros D et al (1994). Prefrontal and temporal blood flow in schizophrenia: resting and activation technetium-99m-hmpao spect patterns in young neuroleptic-naive patients with acute disease. J Nucl Med 35: 935-941.

Chang C, Crottaz-Herbette S, Menon V (2007). Temporal dynamics of basal ganglia response and connectivity during verbal working memory. Neuroimage 34: 1253-1269.

Chowdari KV, Mirnics K, Semwal P, Wood J, Lawrence E, Bhatia T et al (2002). Association and linkage analyses of rgs4 polymorphisms in schizophrenia. Hum Mol Genet 11: 1373-1380.

Clark D, Dedova I, Cordwell S, Matsumoto I (2006). A proteome analysis of the anterior cingulate cortex gray matter in schizophrenia. Mol Psychiatry 11: 459-470.

Cohen JD, Perlstein WM, Braver TS, Nystrom LE, Noll DC, Jonides J et al (1997). Temporal dynamics of brain activation during a working memory task. Nature 386: 604-608. Support for differential functional topography during different stages of working memory task performance.
Curtis VA, Bullmore ET, Brammer MJ, Wright IC, Williams SC, Morris RG et al (1998). Attenuated frontal activation during a verbal fluency task in patients with schizophrenia. Am J Psychiatry 155: 1056-1063.

Curtis VA, Bullmore ET, Morris RG, Brammer MJ, Williams SCR, Simmons A et al (1999). Attenuated frontal activation in schizophrenia may be task dependent. Schizophr Res 37: 35-44.

Daniel D, Weinberger D, Jones D, Zigun J, Coppola R, Handel S et al (1991). The effect of amphetamine on regional cerebral blood flow during cognitive activation in schizophrenia. J Neurosci 11: 1907-1917.

Dao-Castellana M-H, Paillère-Martinot M-L, Hantraye $P$, Attar-Lévy D, Rémy $P$, Crouzel C et al (1997). Presynaptic dopaminergic function in the striatum of schizophrenic patients. Schizophr Res 23: 167-174.

Daviss SR, Lewis DA (1995). Local circuit neurons of the prefrontal cortex in schizophrenia: selective increase in the density of calbindin-immunoreactive neurons. Psychiatry Res 59: 81-96.

Deicken RF, Johnson C, Eliaz Y, Schuff N (2000). Reduced concentrations of thalamic n-acetylaspartate in male patients with schizophrenia. Am J Psychiatry 157: 644-647

Dolan RJ, Fletcher P, Frith CD, Friston KJ, Frackowiak RS, Grasby PM (1995). Dopaminergic modulation of impaired cognitive activation in the anterior cingulate cortex in schizophrenia. Nature 378: 180-182. First evidence in live humans showing that dopaminergic agents can modify cognitive physiology.

Drevets WC, Raichle ME (1998). Suppression of regional cerebral blood during emotional versus higher cognitive implications for interactions between emotion and cognition. Cogn Emot 12: 353-385.

Driesen NR, Leung H-C, Calhoun VD, Constable RT, Gueorguieva R, Hoffman R et al (2008). Impairment of working memory maintenance and response in schizophrenia: functional magnetic resonance imaging evidence. Biol Psychiatry 64: 1026-1034.

Dunnett SB, Meldrum A, Muir JL (2005). Frontal-striatal disconnection disrupts cognitive performance of the frontal-type in the rat. Neuroscience 135: 1055-1065.

Durany N, Michel T, Zöchling R, Boissl KW, Cruz-Sánchez FF, Riederer $\mathrm{P}$ et al (2001). Brain-derived neurotrophic factor and neurotrophin 3 in schizophrenic psychoses. Schizophr Res 52: 79-86

Eack SM, George MM, Prasad KMR, Keshavan MS (2008). Neuroanatomical substrates of foresight in schizophrenia. Schizophr Res 103: 62-70.

Egan MF, Goldberg TE, Kolachana BS, Callicott JH, Mazzanti CM, Straub RE et al (2001). Effect of comt val108/158 met genotype on frontal lobe function and risk for schizophrenia. Proc Natl Acad Sci USA 98: 6917-6922. Seminal paper showing effect of COMT allelic load on prefrontal physiology and n-back task performance.

Egan MF, Straub RE, Goldberg TE, Yakub I, Callicott JH, Hariri AR et al (2004). Variation in grm3 affects cognition, prefrontal glutamate, and risk for schizophrenia. Proc Natl Acad Sci USA 101: 12604-12609. First demonstration of an association between GRM3 polymorphism and neuropsychological, spectroscopic, and diagnostic measures.

Ekelund J, Hennah W, Hiekkalinna T, Parker A, Meyer J, Lonnqvist J et al (2004). Replication of 1q42 linkage in finnish schizophrenia pedigrees. Mol Psychiatry 9: 1037-1041.

Elkashef AM, Doudet D, Bryant T, Cohen RM, Li S-H, Wyatt RJ (2000). 6-18f-dopa pet study in patients with schizophrenia. Psychiatry Res 100: 1-11.

Elvevag B, Goldberg TE (2000). Cognitive impairment in schizophrenia is the core of the disorder. Crit Rev Neurobiol 14: 1-21.

Emamian ES, Hall D, Birnbaum MJ, Karayiorgou M, Gogos JA (2004). Convergent evidence for impaired akt1-gsk3beta signaling in schizophrenia. Nat Genetics 36: 131-137.

Ende G, Braus DF, Walter S, Henn FA (2001). Lower concentration of thalamic n-acetylaspartate in patients with schizophrenia: a replication study. $\mathrm{Am} \mathrm{J}$ Psychiatry 158: 1314-1316.

Eslinger PJ, Grattan LM (1993). Frontal lobe and frontal-striatal substrates for different forms of human cognitive flexibility. Neuropsychologia 31: 17-28.

Esslinger C, Walter H, Kirsch P, Erk S, Schnell K, Arnold C et al (2009). Neural mechanisms of a genome-wide supported psychosis variant. Science 324: 605. First paper to show that a SNP discovered via genome-wide association study can demonstrate schizophrenia imaging phenotypes.

Fitzsimmons J, Kubicki M, Smith K, Bushell G, Estepar RSJ, Westin C-F et al (2009). Diffusion tractography of the fornix in schizophrenia. Schizophr Res 107: 39-46.

Fletcher PC, Frith CD, Grasby PM, Friston KJ, Dolan RJ (1996). Local and distributed effects of apomorphine on fronto-temporal function in acute unmedicated schizophrenia. J Neurosci 16: 7055-7062.

Fletcher PC, McKenna PJ, Frith CD, Grasby PM, Friston KJ, Dolan RJ (1998). Brain activations in schizophrenia during a graded memory task studied with functional neuroimaging. Arch Gen Psychiatry 55: 1001-1008. 
Flores G, Wood GK, Liang JJ, Quirion R, Srivastava LK (1996). Enhanced amphetamine sensitivity and increased expression of dopamine $\mathrm{d} 2$ receptors in postpubertal rats after neonatal excitotoxic lesions of the medial prefrontal cortex. J Neurosci 16: 7366-7375.

Ford JM, Gray M, Whitfield SL, Turken AU, Glover G, Faustman WO et al (2004). Acquiring and inhibiting prepotent responses in schizophrenia: event-related brain potentials and functional magnetic resonance imaging. Arch Gen Psychiatry 61: 119-129.

Fornito A, Yücel M, Patti J, Wood SJ, Pantelis C (2009). Mapping grey matter reductions in schizophrenia: an anatomical likelihood estimation analysis of voxel-based morphometry studies. Schizophr Res 108: 104-113.

Frank MJ, Loughry B, O'reilly RC (2001). Interactions between frontal cortex and basal ganglia in working memory: a computational model. Cogn Affec Behav Neurosci 1: 137-160.

Frederikse M, Lu A, Aylward E, Barta P, Sharma T, Pearlson G (2000). Sex differences in inferior parietal lobule volume in schizophrenia. Am J Psychiatry 157: 422-427.

Frith CD, Friston KJ, Liddle PF, Frackowiak RSJ (1991). A pet study of word finding Neuropsychologia 29: 1137-1148.

Fu CHY, Suckling J, Williams SCR, Andrew CM, Vythelingum GN, McGuire PK (2005). Effects of psychotic state and task demand on prefrontal function in schizophrenia: an fmri study of overt verbal fluency. Am J Psychiatry 162: 485-494.

Gao X-M, Sakai K, Roberts RC, Conley RR, Dean B, Tamminga CA (2000). Ionotropic glutamate receptors and expression of n-methyl-d-aspartate receptor subunits in subregions of human hippocampus: effects of schizophrenia. Am J Psychiatry 157: 1141-1149.

Gilbody S, Lewis S, Lightfoot T (2007). Methylenetetrahydrofolate reductase (mthfr) genetic polymorphisms and psychiatric disorders: a huge review. Am J Epidemiol 165: 1-13.

Giuliani NR, Calhoun VD, Pearlson GD, Francis A, Buchanan RW (2005). Voxelbased morphometry versus region of interest: a comparison of two methods for analyzing gray matter differences in schizophrenia. Schizophr Res 74: 135-147.

Glahn DC, Ragland JD, Abramoff A, Barrett J, Laird AR, Bearden CE et al (2005). Beyond hypofrontality: a quantitative meta-analysis of functional neuroimaging studies of working memory in schizophrenia. Hum Brain Mapp 25: 60-69. An excellent meta-analysis of working memory functional imaging.

Glantz LA, Lewis DA (2000). Decreased dendritic spine density on prefrontal cortical pyramidal neurons in schizophrenia. Arch Gen Psychiatry 57: 65-73.

Goldberg TE, Berman KF, Fleming K, Ostrem J, Van Horn JD, Esposito G et al (1998). Uncoupling cognitive workload and prefrontal cortical physiology: a pet rcbf study. Neuroimage 7: 296-303.

Goldberg TE, Berman KF, Mohr E, Weinberger DR (1990). Regional cerebral blood flow and cognitive function in Huntington's disease and schizophrenia: a comparison of patients matched for performance on a prefrontal-type task. Arch Neurol 47: 418-422.

Goldman PS, Rosvold HE (1972). The effects of selective caudate lesions in infant and juvenile rhesus monkeys. Brain Res 43: 53-66.

Goldstein JM, Goodman JM, Seidman LJ, Kennedy DN, Makris N, Lee H et al (1999). Cortical abnormalities in schizophrenia identified by structural magnetic resonance imaging. Arch Gen Psychiatry 56: 537-547.

Gottesman II, Sheilds J (1972). Schizophrenia and Genetics: A Twin Study Vantage Point. Academic Press: New York.

Gourovitch ML, Kirkby BS, Goldberg TE, Weinberger DR, Gold JM, Esposito G et al (2000). A comparison of rcbf patterns during letter and semantic fluency. Neuropsychology 14: 353-360.

Graham S, Phua E, Soon CS, Oh T, Au C, Shuter B et al (2009). Role of medial cortical, hippocampal and striatal interactions during cognitive set-shifting. Neuroimage 45: 1359-1367.

Guo N, Hwang D-R, Lo E-S, Huang Y-Y, Laruelle M, Abi-Dargham A (2003). Dopamine depletion and in vivo binding of pet $\mathrm{d} 1$ receptor radioligands: implications for imaging studies in schizophrenia. Neuropsychopharmacology 28: 1703-1711.

Gur RE, Maany V, Mozley PD, Swanson C, Bilker W, Gur RC (1998). Subcortical mri volumes in neuroleptic-naive and treated patients with schizophrenia. Am J Psychiatry 155: 1711-1717.

Hall J, Whalley HC, Job DE, Baig BJ, Mclntosh AM, Evans KL et al (2006). A neuregulin 1 variant associated with abnormal cortical function and psychotic symptoms. Nat Neurosci 9: 1477-1478.

Harrison PJ, McLaughlin D, Kerwin RW (1991). Decreased hippocampal expression of a glutamate receptor gene in schizophrenia. Lancet 337: 450-452.

Hazlett EA, Buchsbaum MS, Kemether E, Bloom R, Platholi J, Brickman AM et al (2004). Abnormal glucose metabolism in the mediodorsal nucleus of the thalamus in schizophrenia. Am J Psychiatry 161: 305-314.
Hennah W, Varilo T, Kestila M, Paunio T, Arajarvi R, Haukka J et al (2003). Haplotype transmission analysis provides evidence of association for disc1 to schizophrenia and suggests sex-dependent effects. Hum Mol Genet 12: 3151-3159.

Hietala J, Syvälahti E, Kuoppamäki M, Hietala J, Syvälahti E, Haaparanta M et al (1995). Presynaptic dopamine function in striatum of neuroleptic-naive schizophrenic patients. Lancet 346: 1130-1131.

Hietala J, Syvälahti E, Vilkman H, Vuorio K, Räkköläinen V, Bergman J et al (1999). Depressive symptoms and presynaptic dopamine function in neuroleptic-naive schizophrenia. Schizophr Res 35: 41-50.

Highley JR, Walker MA, McDonald B, Crow TJ, Esiri MM (2003). Size of hippocampal pyramidal neurons in schizophrenia. Br J Psychiatry 183: 414-417.

Hodgkinson CA, Goldman D, Jaeger J, Persaud S, Kane JM, Lipsky RH et al (2004). Disrupted in schizophrenia 1 (disc1): association with schizophrenia, schizoaffective disorder, and bipolar disorder. Am J Hum Genet 75: 862-872.

Holmes AJ, MacDonald III A, Carter CS, Barch DM, Andrew Stenger V, Cohen JD (2005). Prefrontal functioning during context processing in schizophrenia and major depression: an event-related fmri study. Schizophr Res 76: 199-206.

Holt DJ, Herman MM, Hyde TM, Kleinman JE, Sinton CM, German DC et al (1999). Evidence for a deficit in cholinergic interneurons in the striatum in schizophrenia. Neuroscience 94: 21-31.

Honea R, Crow TJ, Passingham D, Mackay CE (2005). Regional deficits in brain volume in schizophrenia: a meta-analysis of voxel-based morphometry studies. Am J Psychiatry 162: 2233-2245.

Honey GD, Pomarol-Clotet E, Corlett PR, Honey RAE, Mckenna PJ, Bullmore ET et al (2005). Functional dysconnectivity in schizophrenia associated with attentional modulation of motor function. Brain 128: 2597-2611.

Howes OD, Montgomery AJ, Asselin M-C, Murray RM, Valli I, Tabraham P et al (2009). Elevated striatal dopamine function linked to prodromal signs of schizophrenia. Arch Gen Psychiatry 66: 13-20.

Huang H-S, Akbarian S (2007). Gad1 mrna expression and DNA methylation in prefrontal cortex of subjects with schizophrenia. PLOS ONE 2: e809.

Hulshoff Pol HE, Schnack HG, Mandl RCW, van Haren NEM, Koning H, Collins DL et al (2001). Focal gray matter density changes in schizophrenia. Arch Gen Psychiatry 58: 1118-1125.

Ibrahim HM, Hogg Jr AJ, Healy DJ, Haroutunian V, Davis KL, Meador-Woodruff JH (2000). Ionotropic glutamate receptor binding and subunit mrna expression in thalamic nuclei in schizophrenia. Am J Psychiatry 157: 1811-1823.

Ingvar D, Franzén G (1974). Distribution of cerebral activity in chronic schizophrenia. Lancet 304: 1484-1486. Seminal paper first describing in vivo hypofrontality in schizophrenia.

Ishikawa M, Mizukami K, Iwakiri M, Asada T (2007). Immunohistochemical and immunoblot analysis of dopamine and cyclic amp-regulated phosphoprotein relative molecular mass 32000 (darpp-32) in the prefrontal cortex of subjects with schizophrenia and bipolar disorder. Prog Neuropsychopharmacol Biol Psychiatry 31: 1177-1181.

Jansma JM, Ramsey NF, van der Wee NJA, Kahn RS (2004). Working memory capacity in schizophrenia: a parametric fmri study. Schizophr Res 68 159-171.

Jaskiw GE, Karoum F, Freed WJ, Phillips I, Kleinman JE, Weinberger DR (1990a). Effect of ibotenic acid lesions of the medial prefrontal cortex on amphetamineinduced locomotion and regional brain catecholamine concentrations in the rat. Brain Res 534: 263-272.

Jaskiw GE, Karoum FK, Weinberger DR (1990b). Persistent elevations in dopamine and its metabolites in the nucleus accumbens after mild subchronic stress in rats with ibotenic acid lesions of the medial prefrontal cortex. Brain Res 534: 321-323.

Jaskiw GE, Weinberger DR, Crawley JN (1991). Microinjection of apomorphine into the prefrontal cortex of the rat reduces dopamine metabolite concentrations in microdialysate from the caudate nucleus. Biol Psychiatry 29: 703-706.

Johnson MR, Morris NA, Astur RS, Calhoun VD, Mathalon DH, Kiehl KA et al (2006). A functional magnetic resonance imaging study of working memory abnormalities in schizophrenia. Biol Psychiatry 60: 11-21.

Jonides J, Schumacher EH, Smith EE, Koeppe RA, Awh E, Reuter-Lorenz PA et al (1998). The role of parietal cortex in verbal working memory. J Neurosci 18: 5026-5034.

Kaladjian A, Jeanningros R, Azorin J-M, Grimault S, Anton J-L, Mazzola-Pomietto P (2007). Blunted activation in right ventrolateral prefrontal cortex during motor response inhibition in schizophrenia. Schizophr Res 97: 184-193.

Kamiya A, Kubo K-i, Tomoda T, Takaki M, Youn R, Ozeki Y et al (2005). A schizophrenia-associated mutation of disc1 perturbs cerebral cortex development. Nat Cell Biol 7: 1167-1178.

Karlsgodt KH, Glahn DC, van Erp TGM, Therman S, Huttunen M, Manninen M et al (2007). The relationship between performance and fmri signal during working memory in patients with schizophrenia, unaffected co-twins, and control subjects. Schizophr Res 89: 191-197. 
Karlsgodt KH, Sanz J, van Erp TGM, Bearden CE, Nuechterlein KH, Cannon TD (2009). Re-evaluating dorsolateral prefrontal cortex activation during working memory in schizophrenia. Schizophr Res 108: 143-150.

Kastner A, Anglade P, Bounaix C, Damier P, Javoyagid F, Bromet N et al (1994). Immunohistochemical study of catechol-o-methyltransferase in the human mesostriatal system. Neuroscience 62: 449-457.

Kawasaki Y, Suzuki M, Maeda Y, Urata K, Yamaguchi N, Matsuda H et al (1992). Regional cerebral blood flow in patients with schizophrenia. A preliminary report. Eur Arch Psychiatry Clin Neurosci 241: 195-200.

Kempf L, Nicodemus KK, Kolachana B, Vakkalanka R, Verchinski BA, Egan MF et al (2008). Functional polymorphisms in prodh are associated with risk and protection for schizophrenia and fronto-striatal structure and function. PLOS Genet 4: e1000252. Demonstration of association between genetic variation in PRODH and both risk of schizophrenia and associated neuroimaging phenotypes.

Kerns JG, Cohen JD, MacDonald III AW, Johnson MK, Stenger VA, Aizenstein H et al (2005). Decreased conflict- and error-related activity in the anterior cingulate cortex in subjects with schizophrenia. Am J Psychiatry 162: 1833-1839.

Kestler LP, Walker E, Vega EM (2001). Dopamine receptors in the brains of schizophrenia patients: a meta-analysis of the findings. Behav Pharmacol 12: 355-371.

Kim J-J, Kwon JS, Park HJ, Youn T, Kang DH, Kim MS et al (2003). Functional disconnection between the prefrontal and parietal cortices during working memory processing in schizophrenia: a [15o]h2o pet study. Am J Psychiatry 160: 919-923. A demonstration of frontoparietal disconnection during working memory.

Kindermann SS, Brown GG, Zorrilla LE, Olsen RK, Jeste DV (2004). Spatial working memory among middle-aged and older patients with schizophrenia and volunteers using fmri. Schizophr Res 68: 203-216.

Kircher T, Krug A, Markov V, Whitney C, Krach S, Zerres K et al (2009). Genetic variation in the schizophrenia-risk gene neuregulin 1 correlates with brain activation and impaired speech production in a verbal fluency task in healthy individuals. Hum Brain Mapp 9999: NA.

Ko JH, Ptito A, Monchi O, Cho SS, Van Eimeren T, Pellecchia G et al (2009). Increased dopamine release in the right anterior cingulate cortex during the performance of a sorting task: a [11c]flb 457 pet study. Neuroimage 46: 516-521.

Koch K, Wagner G, Nenadic I, Schachtzabel C, Schultz C, Roebel M et al (2008). Fronto-striatal hypoactivation during correct information retrieval in patients with schizophrenia: an fmri study. Neuroscience 153: 54-62.

Kolachana BS, Saunders RC, Weinberger DR (1995). Augmentation of prefrontal cortical monoaminergic activity inhibits dopamine release in the caudate nucleus: an in vivo neurochemical assessment in the rhesus monkey. Neuroscience 69: 859-868

Kolomeets NS, Orlovskaya DD, Uranova NA (2007). Decreased numerical density of ca3 hippocampal mossy fiber synapses in schizophrenia. Synapse 61: 615-621.

Konick LC, Friedman L (2001). Meta-analysis of thalamic size in schizophrenia. Biol Psychiatry 49: 28-38.

Krabbendam L, O'Daly O, Morley LA, van Os J, Murray RM, Shergill SS (2009). Using the stroop task to investigate the neural correlates of symptom change in schizophrenia. Br J Psychiatry 194: 373-374.

Kraepelin E (1909-1913). Psychiatrie Vol 2. J.A. Barth: Leipzig

Kubicki M, Shenton ME, Salisbury DF, Hirayasu Y, Kasai K, Kikinis R et al (2002). Voxel-based morphometric analysis of gray matter in first episode schizophrenia. Neuroimage 17: 1711-1719.

Kubicki M, Westin C-F, Nestor PG, Wible CG, Frumin M, Maier SE et al (2003). Cingulate fasciculus integrity disruption in schizophrenia: a magnetic resonance diffusion tensor imaging study. Biol Psychiatry 54: 1171-1180.

Kung L, Conley R, Chute DJ, Smialek J, Roberts RC (1998). Synaptic changes in the striatum of schizophrenic cases: a controlled postmortem ultrastructural study. Synapse 28: 125-139.

Kung L, Roberts RC (1999). Mitochondrial pathology in human schizophrenic striatum: a postmortem ultrastructural study. Synapse 31: 67-75.

Kunimatsu N, Aoki S, Kunimatsu A, Yoshida M, Abe O, Yamada H et al (2008). Tract-specific analysis of the superior occipitofrontal fasciculus in schizophrenia. Psychiatry Res 164: 198-205.

Kuperberg GR, West WC, Lakshmanan BM, Goff D (2008). Functional magnetic resonance imaging reveals neuroanatomical dissociations during semantic integration in schizophrenia. Biol Psychiatry 64: 407-418.

Kurtz MM, Moberg PJ, Ragland JD, Gur RC, Gur RE (2005). Symptoms versus neurocognitive test performance as predictors of psychosocial status in schizophrenia: a 1- and 4-year prospective study. Schizophr Bull 31: 167-174.

Landau SM, Lal R, O'Neil JP, Baker S, Jagust WJ (2009). Striatal dopamine and working memory. Cereb Cortex 19: 445-454.
Laruelle M (1998). Imaging dopamine transmission in schizophrenia. A review and meta-analysis. Q J Nucl Med 42: 211-221.

Laruelle M, Abi-Dargham A, van Dyck CH, Gil R, D'Souza CD, Erdos J et al (1996). Single photon emission computerized tomography imaging of amphetamineinduced dopamine release in drug-free schizophrenic subjects. Proc Natl Acad Sci USA 93: 9235-9240. First in vivo evidence of exaggerated amphetamineinduced striatal dopamine release in schizophrenia.

Laurens KR, Ngan ETC, Bates AT, Kiehl KA, Liddle PF (2003). Rostral anterior cingulate cortex dysfunction during error processing in schizophrenia. Brain 126: 610-622.

Law AJ, Lipska BK, Weickert CS, Hyde TM, Straub RE, Hashimoto R et al (2006). Neuregulin 1 transcripts are differentially expressed in schizophrenia and regulated by $5^{\prime}$ snps associated with the disease. Proc Natl Acad Sci USA 103: $6747-6752$

Law AJ, Weickert CS, Hyde TM, Kleinman JE, Harrison PJ (2004). Reduced spinophilin but not microtubule-associated protein 2 expression in the hippocampal formation in schizophrenia and mood disorders: molecular evidence for a pathology of dendritic spines. Am J Psychiatry 161: 1848-1855.

Lee J, Folley BS, Gore J, Park S (2008). Origins of spatial working memory deficits in schizophrenia: an event-related fmri and near-infrared spectroscopy study. PLOS ONE 3: e1760.

Lewis SJG, Dove A, Robbins TW, Barker RA, Owen AM (2004). Striatal contributions to working memory: a functional magnetic resonance imaging study in humans. Eur J Neurosci 19: 755-760.

Li D, Collier DA, He L (2006). Meta-analysis shows strong positive association of the neuregulin 1 (nrg1) gene with schizophrenia. Hum Mol Genet 15: 1995-2002.

Liddle PF (2000). Cognitive impairment in schizophrenia: its impact on social functioning. Acta Psychiatr Scand Supp/ 400: 11-16.

Lindström LH, Gefvert O, Hagberg G, Lundberg T, Bergström M, Hartvig P et al (1999). Increased dopamine synthesis rate in medial prefrontal cortex and striatum in schizophrenia indicated by -([beta]-11c) dopa and pet. Biol Psychiatry 46: 681-688.

Lipska BK, Aultman JM, Verma A, Weinberger DR, Moghaddam B (2002). Neonatal damage of the ventral hippocampus impairs working memory in the rat. Neuropsychopharmacology 27: 47-54. Neurodevelopmental model of prefrontal dysfunction via neonatal ventral hippocampal damage.

Lipska BK, Mitkus S, Caruso M, Hyde TM, Chen J, Vakkalanka R et al (2006a). Rgs4 mrna expression in postmortem human cortex is associated with comt val158met genotype and comt enzyme activity. Hum Mol Genet 15: 2804-2812.

Lipska BK, Peters T, Hyde TM, Halim N, Horowitz C, Mitkus S et al (2006b). Expression of disc1 binding partners is reduced in schizophrenia and associated with disc1 snps. Hum Mol Genet 15: 1245-1258.

Lipska BK, Weinberger DR (2000). To model a psychiatric disorder in animals: schizophrenia as a reality test. Neuropsychopharmacology 23: 223-239.

Liu J, Pearlson G, Windemuth A, Ruano G, Perrone-Bizzozero NI, Calhoun V (2009). Combining fmri and snp data to investigate connections between brain function and genetics using parallel ica. Hum Brain Mapp 30: 241-255.

Liu Z, Tam WC, Xie Y, Zhao J (2002). The relationship between regional cerebral blood flow and the wisconsin card sorting test in negative schizophrenia. Psychiatry Clin Neurosci 56: 3-7.

Lumme V, Aalto S, llonen T, Någren K, Hietala J (2007). Dopamine d2/d3 receptor binding in the anterior cingulate cortex and executive functioning. Psychiatry Res 156: $69-74$.

MacDonald AW, Cohen JD, Stenger VA, Carter CS (2000). Dissociating the role of the dorsolateral prefrontal and anterior cingulate cortex in cognitive control. Science 288: 1835-1838.

MacDonald III AW, Carter CS, Kerns JG, Ursu S, Barch DM, Holmes AJ et al (2005). Specificity of prefrontal dysfunction and context processing deficits to schizophrenia in never-medicated patients with first-episode psychosis. Am J Psychiatry 162: 475-484.

MacDonald III AW, Thermenos HW, Barch DM, Seidman LJ (2008). Imaging genetic liability to schizophrenia: systematic review of fmri studies of patients' nonpsychotic relatives. Schizophr Bull 053.

Mackay AVP, Iversen LL, Rossor M, Spokes E, Bird E, Arregui A et al (1982). Increased brain dopamine and dopamine receptors in schizophrenia. Arch Gen Psychiatry 39: 991-997.

Mallet L, Mazoyer B, Martinot J-L (1998). Functional connectivity in depressive, obsessive-compulsive, and schizophrenic disorders: an explorative correlational analysis of regional cerebral metabolism. Psychiatry Res 82: 83-93.

Manoach DS (2003). Prefrontal cortex dysfunction during working memory performance in schizophrenia: reconciling discrepant findings. Schizophr Res 60: 285-298.

Manoach DS, Gollub RL, Benson ES, Searl MM, Goff DC, Halpern E et al (2000). Schizophrenic subjects show aberrant fmri activation of dorsolateral prefrontal cortex and basal ganglia during working memory performance. Biol Psychiatry 
48: 99-109. In vivo evidence for frontostriatal dysfunction during working memory in schizophrenia.

Manoach DS, Press DZ, Thangaraj V, Searl MM, Goff DC, Halpern E et al (1999). Schizophrenic subjects activate dorsolateral prefrontal cortex during a working memory task, as measured by fmri. Biol Psychiatry 45: 1128-1137.

Marenco S, Steele SU, Egan MF, Goldberg TE, Straub RE, Sharrief AZ et al (2006). Effect of metabotropic glutamate receptor 3 genotype on n-acetylaspartate measures in the dorsolateral prefrontal cortex. Am J Psychiatry 163: 740-742.

Maruff P, Wood SJ, Velakoulis D, Smith DJ, Soulsby B, Suckling J et al (2005). Reduced volume of parietal and frontal association areas in patients with schizophrenia characterized by passivity delusions. Psychol Med 35: 783-789.

Mattay VS, Goldberg TE, Fera F, Hariri AR, Tessitore A, Egan MF et al (2003). Catechol o-methyltransferase val158-met genotype and individual variation in the brain response to amphetamine. Proc Natl Acad Sci USA 100: 6186-6191. First demonstration of hypothesized inverted U-shaped prefrontal dopamineBOLD activation curve using both genetic information and pharmacological manipulation.

McDowell JE, Brown GG, Paulus M, Martinez A, Stewart SE, Dubowitz DJ et al (2002). Neural correlates of refixation saccades and antisaccades in normal and schizophrenia subjects. Biol Psychiatry 51: 216-223.

McGowan S, Lawrence AD, Sales T, Quested D, Grasby P (2004). Presynaptic dopaminergic dysfunction in schizophrenia: a positron emission tomographic [18fffluorodopa study. Arch Gen Psychiatry 61: 134-142.

Mclntosh AM, Moorhead TWJ, Job D, Lymer GKS, Munoz Maniega S, McKirdy J et al (2007). The effects of a neuregulin 1 variant on white matter density and integrity. Mol Psychiatry 13: 1054-1059. First paper to report an association between NRG1 and white matter integrity, in line with neuregulin's proposed roles in neurodevelopment, axonal guidance, and myelination.

Meda SA, Giuliani NR, Calhoun VD, Jagannathan K, Schretlen DJ, Pulver A et al (2008). A large scale $(n=400)$ investigation of gray matter differences in schizophrenia using optimized voxel-based morphometry. Schizophr Res 101: 95-105.

Medalla M, Barbas H (2009). Synapses with inhibitory neurons differentiate anterior cingulate from dorsolateral prefrontal pathways associated with cognitive control. Neuron 61: 609-620.

Mei L, Xiong W-C (2008). Neuregulin 1 in neural development, synaptic plasticity and schizophrenia. Nat Rev Neurosci 9: 437-452.

Mendrek A, Laurens KR, Kiehl KA, Ngan ETC, Stip E, Liddle PF (2004). Changes in distributed neural circuitry function in patients with first-episode schizophrenia. Br J Psychiatry 185: 205-214.

Meyer-Lindenberg A, Kohn PD, Kolachana B, Kippenhan S, Mclnerney-Leo A, Nussbaum $R$ et al (2005a). Midbrain dopamine and prefrontal function in humans: interaction and modulation by comt genotype. Nat Neurosci 8 594-596.

Meyer-Lindenberg A, Miletich RS, Kohn PD, Esposito G, Carson RE, Quarantelli M et al (2002). Reduced prefrontal activity predicts exaggerated striatal dopaminergic function in schizophrenia. Nat Neurosci 5: 267-271. First paper to show a link between hypoactivation in prefrontal cortex and abnormally high presynaptic dopamine measured in the striatum.

Meyer-Lindenberg A, Nichols T, Callicott JH, Ding J, Kolachana B, Buckholtz J et al (2006). Impact of complex genetic variation in COMT on human brain function. Mol Psychiatry 11: 867-877.

Meyer-Lindenberg A, Poline J-B, Kohn PD, Holt JL, Egan MF, Weinberger DR et al (2001). Evidence for abnormal cortical functional connectivity during working memory in schizophrenia. Am J Psychiatry 158: 1809-1817.

Meyer-Lindenberg A, Straub RE, Lipska BK, Verchinski BA, Goldberg T, Callicott JH et al (2007). Genetic evidence implicating darpp-32 in human frontostriatal structure, function, and cognition. J Clin Invest 117: 672-682. First report demonstrating structural, functional, and cognitive correlates of PPP1R1B variation that are remarkably similar to schizophrenia neuroimaging phenotypes.

Meyer-Lindenberg AS, Olsen RK, Kohn PD, Brown T, Egan MF, Weinberger DR et al (2005b). Regionally specific disturbance of dorsolateral prefrontal-hippocampal functional connectivity in schizophrenia. Arch Gen Psychiatry 62: 379-386. First demonstration of inappropriately persistent DLPFC-hippocampal functional connectivity.

Middleton FA, Strick PL (2002). Basal-ganglia 'projections' to the prefrontal cortex of the primate. Cereb Cortex 12: 926-935.

Mier D, Kirsch P, Meyer-Lindenberg A (2009). Neural substrates of pleiotropic action of genetic variation in comt: a meta-analysis. Mol Psychiatry advance online publication (doi:10.1038/mp.2009.36).

Mirnics K, Middleton FA, Stanwood GD, Lewis DA, Levitt P (2001). Disease-specific changes in regulator of g-protein signaling 4 (rgs4) expression in schizophrenia. Mol Psychiatry 6: 293-301.

Mitelman SA, Byne W, Kemether EM, Hazlett EA, Buchsbaum MS (2005). Metabolic disconnection between the mediodorsal nucleus of the thalamus and cortical brodmann's areas of the left hemisphere in schizophrenia. Am J Psychiatry 162: 1733-1735.

Monchi O, Petrides M, Petre V, Worsley K, Dagher A (2001). Wisconsin card sorting revisited: distinct neural circuits participating in different stages of the task identified by event-related functional magnetic resonance imaging. J Neurosci 21: $7733-7741$.

Murray A, Hyde T, Knable M, Herman M, Bigelow L, Carter J et al (1995). Distribution of putative $\mathrm{d} 4$ dopamine receptors in postmortem striatum from patients with schizophrenia. J Neurosci 15: 2186-2191.

Nelson MD, Saykin AJ, Flashman LA, Riordan HJ (1998). Hippocampal volume reduction in schizophrenia as assessed by magnetic resonance imaging: a metaanalytic study. Arch Gen Psychiatry 55: 433-440.

Nicodemus KK, Marenco S, Batten AJ, Vakkalanka R, Egan MF, Straub RE et al (2008). Serious obstetric complications interact with hypoxia-regulated//vascular-expression genes to influence schizophrenia risk. Mol Psychiatry 13: 873-877

Nierenberg J, Salisbury DF, Levitt JJ, David EA, McCarley RW, Shenton ME (2005). Reduced left angular gyrus volume in first-episode schizophrenia. Am J Psychiatry 162: 1539-1541.

Niznikiewicz M, Donnino R, McCarley RW, Nestor PG, losifescu DV, O'Donnell B et al (2000). Abnormal angular gyrus asymmetry in schizophrenia. Am J Psychiatry 157: 428-437.

Nopoulos P, Torres I, Flaum M, Andreasen N, Ehrhardt J, Yuh W (1995). Brain morphology in first-episode schizophrenia. Am J Psychiatry 152: 1721-1723.

Nozaki S, Kato M, Takano H, Ito H, Takahashi H, Arakawa R et al (2009). Regional dopamine synthesis in patients with schizophrenia using I-[[beta]-11c]dopa pet. Schizophr Res 108: 78-84.

O'Donovan MC, Craddock N, Norton N, Williams H, Peirce T, Moskvina V et al (2008). Identification of loci associated with schizophrenia by genome-wide association and follow-up. Nat Genet 40: 1053-1055.

Ohrmann P, Kugel H, Bauer J, Siegmund A, Kölkebeck K, Suslow T et al (2008). Learning potential on the wcst in schizophrenia is related to the neuronal integrity of the anterior cingulate cortex as measured by proton magnetic resonance spectroscopy. Schizophr Res 106: 156-163.

Okubo Y, Suhara T, Suzuki K, Kobayashi K, Inoue O, Terasaki O et al (1997). Decreased prefrontal dopamine $\mathrm{d} 1$ receptors in schizophrenia revealed by pet. Nature 385: 634-636.

O'Leary DS, Flaum M, Kesler ML, Flashman LA, Arndt S, Andreasen NC (2000). Cognitive correlates of the negative, disorganized, and psychotic symptom dimensions of schizophrenia. J Neuropsychiatry Clin Neurosci 12: 4-15.

Owen AM, Doyon J, Petrides M, Evans AC (1996). Planning and spatial working memory: a positron emission tomography study in humans. Eur $\mathrm{J}$ Neurosci 8 : 353-364

Pakkenberg B (1990). Pronounced reduction of total neuron number in mediodorsal thalamic nucleus and nucleus accumbens in schizophrenics. Arch Gen Psychiatry 47: 1023-1028.

Pantelis C, Barnes T, Nelson H, Tanner S, Weatherley L, Owen A et al (1997). Frontal-striatal cognitive deficits in patients with chronic schizophrenia. Brain 120: $1823-1843$

Pantelis C, Stuart GW, Nelson HE, Robbins TW, Barnes TRE (2001). Spatial working memory deficits in schizophrenia: relationship with tardive dyskinesia and negative symptoms. Am J Psychiatry 158: 1276-1285.

Pardo JV, Pardo PJ, Janer KW, Raichle ME (1990). The anterior cingulate cortex mediates processing selection in the stroop attentional conflict paradigm. Proc Natl Acad Sci USA 87: 256-259.

Parellada E, Catafau AM, Bernardo M, Lomena F, Catarineu S, Gonzalez-Monclus E (1998). The resting and activation issue of hypofrontality: a single photon emission computed tomography study in neuroleptic-naive and neuroleptic-free schizophrenic female patients. Biol Psychiatry 44: 787-790.

Parellada E, Catafau AM, Bernardo M, Lomena F, Gonzalez-Monclus E, Setoain J (1994). Prefrontal dysfunction in young acute neuroleptic-naive schizophrenic patients: a resting and activation spect study. Psychiatry Res 55: 131-139.

Park H-J, Levitt J, Shenton ME, Salisbury DF, Kubicki M, Kikinis R et al (2004). An mri study of spatial probability brain map differences between first-episode schizophrenia and normal controls. Neuroimage 22: 1231-1246.

Perlstein WM, Carter CS, Noll DC, Cohen JD (2001). Relation of prefrontal cortex dysfunction to working memory and symptoms in schizophrenia. Am J Psychiatry 158: 1105-1113.

Perlstein WM, Dixit NK, Carter CS, Noll DC, Cohen JD (2003). Prefrontal cortex dysfunction mediates deficits in working memory and prepotent responding in schizophrenia. Biol Psychiatry 53: 25-38.

Polli FE, Barton JJS, Thakkar KN, Greve DN, Goff DC, Rauch SL et al (2008). Reduced error-related activation in two anterior cingulate circuits is related to impaired performance in schizophrenia. Brain 131: 971-986. 
Popken GJ, Bunney WE, Potkin SG, Jones EG (2000). Subnucleus-specific loss of neurons in medial thalamus of schizophrenics. Proc Natl Acad Sci USA 97: 9276-9280.

Postle BR, D'Esposito M (1999). Dissociation of human caudate nucleus activity in spatial and nonspatial working memory: an event-related fmri study. Cogn Brain Res 8: 107-115

Potkin SG, Turner JA, Brown GG, McCarthy G, Greve DN, Glover GH et al (2009). Working memory and dlpfc inefficiency in schizophrenia: the fbirn study. Schizophr Bull 35: 19-31.

Potkin SG, Turner JA, Fallon JA, Lakatos A, Keator DB, Guffanti G et al (2008). Gene discovery through imaging genetics: identification of two novel genes associated with schizophrenia. Mol Psychiatry 14: 416-428.

Prasad KMR, Chowdari KV, Nimgaonkar VL, Talkowski ME, Lewis DA, Keshavan MS (2005). Genetic polymorphisms of the rgs4 and dorsolateral prefrontal cortex morphometry among first episode schizophrenia patients. Mol Psychiatry 10: 213-219.

Prata DP, Mechelli A, Fu CHY, Picchioni M, Kane F, Kalidindi S et al (2008). Effect of disrupted-in-schizophrenia-1 on pre-frontal cortical function. Mol Psychiatry 13: 915-917.

Pycock CJ, Kerwin RW, Carter CJ (1980). Effect of lesion of cortical dopamine terminals on subcortical dopamine receptors in rats. Nature 286: 74-77.

Quintana J, Wong T, Ortiz-Portillo E, Kovalik E, Davidson T, Marder SR et al (2003). Prefrontal-posterior parietal networks in schizophrenia: primary dysfunctions and secondary compensations. Biol Psychiatry 53: 12-24.

Ragland JD, Gur RC, Glahn DC, Censits DM, Smith RJ, Lazarev MG et al (1998). Frontotemporal cerebral blood flow change during executive and declarative memory tasks in schizophrenia: a positron emission tomography study. Neuropsychology 12: 399-413.

Ragland JD, Moelter ST, Bhati MT, Valdez JN, Kohler CG, Siegel SJ et al (2008). Effect of retrieval effort and switching demand on fmri activation during semantic word generation in schizophrenia. Schizophr Res 99: 312-323.

Reith J, Benkelfat C, Sherwin A, Yasuhara Y, Kuwabara H, Andermann F et al (1994). Elevated dopa decarboxylase activity in living brain of patients with psychosis. Proc Natl Acad Sci USA 91: 11651-11654.

Roberts RC, Roche JK, Conley RR (2005). Synaptic differences in the postmortem striatum of subjects with schizophrenia: a stereological ultrastructural analysis. Synapse 56: 185-197.

Roberts RC, Roche JK, Conley RR (2008). Differential synaptic changes in the striatum of subjects with undifferentiated versus paranoid schizophrenia. Synapse 62: 616-627.

Roffman JL, Gollub RL, Calhoun VD, Wassink TH, Weiss AP, Ho BC, et al (2008). MTHFR $677 \mathrm{C} \rightarrow$ T genotype disrupts prefrontal function in schizophrenia through an interaction with COMT 158Val $\rightarrow$ Met. Proc Natl Acad Sci 105: 17573-17578.

Rosoklija G, Toomayan G, Ellis SP, Keilp J, Mann JJ, Latov N et al (2000). Structural abnormalities of subicular dendrites in subjects with schizophrenia and mood disorders: preliminary findings. Arch Gen Psychiatry 57: 349-356.

Rubia K, Russell T, Bullmore ET, Soni W, Brammer MJ, Simmons A et al (2001). An fmri study of reduced left prefrontal activation in schizophrenia during normal inhibitory function. Schizophr Res 52: 47-55.

Rubin P, Holm S, Friberg L, Videbech P, Andersen HS, Bendsen BB et al (1991). Altered modulation of prefrontal and subcortical brain activity in newly diagnosed schizophrenia and schizophreniform disorder: a regional cerebral blood flow study. Arch Gen Psychiatry 48: 987-995.

Rubin P, Holm S, Madsen PL, Friberg L, Videbech P, Andersen HS et al (1994). Regional cerebral blood flow distribution in newly diagnosed schizophrenia and schizophreniform disorder. Psychiatry Res 53: 57-75.

Rüsch N, Spoletini I, Wilke M, Bria P, Di Paola M, Di lulio F et al (2007). Prefrontalthalamic-cerebellar gray matter networks and executive functioning in schizophrenia. Schizophr Res 93: 79-89.

Rypma B, Prabhakaran V, Desmond JE, Glover GH, Gabrieli JDE (1999). Loaddependent roles of frontal brain regions in the maintenance of working memory. Neuroimage 9: 216-226.

Sakai T, Oshima A, Nozaki Y, Ida I, Haga C, Akiyama H et al (2008). Changes in density of calcium-binding-protein-immunoreactive gabaergic neurons in prefrontal cortex in schizophrenia and bipolar disorder. Neuropathology 28: 143-150.

Salgado-Pineda P, Junqué C, Vendrell P, Baeza I, Bargalló N, Falcón C et al (2004). Decreased cerebral activation during cpt performance: structural and functional deficits in schizophrenic patients. Neuroimage 21: 840-847.

Saunders RC, Kolachana BS, Bachevalier J, Weinberger DR (1998). Neonatal lesions of the medial temporal lobe disrupt prefrontal cortical regulation of striatal dopamine. Nature 393: 169-171.

Sawada K, Barr AM, Nakamura M, Arima K, Young CE, Dwork AJ et al (2005). Hippocampal complexin proteins and cognitive dysfunction in schizophrenia. Arch Gen Psychiatry 62: 263-272.
Scheuerecker J, Ufer S, Zipse M, Frodl T, Koutsouleris N, Zetzsche Tet al (2008). Cerebral changes and cognitive dysfunctions in medication-free schizophrenia — an fmri study. J Psychiatr Res 42: 469-476.

Schlaepfer T, Harris G, Tien A, Peng L, Lee S, Federman E et al (1994). Decreased regional cortical gray matter volume in schizophrenia. Am J Psychiatry 151: 842-848.

Schlagenhauf F, Wüstenberg T, Schmack K, Dinges M, Wrase J, Koslowski M et al (2008). Switching schizophrenia patients from typical neuroleptics to olanzapine: effects on bold response during attention and working memory. Eur Neuropsychopharmacol 18: 589-599.

Schlösser R, Gesierich T, Kaufmann B, Vucurevic G, Hunsche S, Gawehn J et al (2003). Altered effective connectivity during working memory performance in schizophrenia: a study with fmri and structural equation modeling. Neuroimage 19: $751-763$.

Schlosser R, Gesierich T, Kaufmann B, Vucurevic G, Stoeter P (2003). Altered effective connectivity in drug free schizophrenic patients. Neuroreport 14: 2233-2237.

Schlösser RGM, Koch K, Wagner G, Nenadic I, Roebel M, Schachtzabel C et al (2008). Inefficient executive cognitive control in schizophrenia is preceded by altered functional activation during information encoding: an fmri study. Neuropsychologia 46: 336-347.

Schlösser RGM, Nenadic I, Wagner G, Güllmar D, von Consbruch K, Köhler S et al (2007). White matter abnormalities and brain activation in schizophrenia: a combined dti and fmri study. Schizophr Res 89: 1-11.

Schneider F, Habel U, Reske M, Kellermann T, Stöcker T, Shah NJ et al (2007). Neural correlates of working memory dysfunction in first-episode schizophrenia patients: an fmri multi-center study. Schizophr Res 89: 198-210.

Seeman P, Guan HC, Van Tol HH (1993). Dopamine d4 receptors elevated in schizophrenia. Nature 365: 441-445. Influential paper implicating striatal D4 receptor upregulation in schizophrenia.

Selemon LD, Mrzljak J, Kleinman JE, Herman MM, Goldman-Rakic PS (2003). Regional specificity in the neuropathologic substrates of schizophrenia: a morphometric analysis of broca's area 44 and area 9. Arch Gen Psychiatry 60: 69-77.

Selemon LD, Rajkowska G, Goldman-Rakic PS (1995). Abnormally high neuronal density in the schizophrenic cortex. A morphometric analysis of prefrontal area 9 and occipital area 17. Arch Gen Psychiatry 52: 805-818; discussion 819-820.

Selemon LD, Rajkowska G, Goldman-Rakic PS (1998). Elevated neuronal density in prefrontal area 46 in brains from schizophrenic patients: application of a threedimensional, stereologic counting method. J Comp Neurol 392: 402-412.

Shergill SS, Kanaan RA, Chitnis XA, O'Daly O, Jones DK, Frangou S et al (2007). A diffusion tensor imaging study of fasciculi in schizophrenia. Am J Psychiatry 164: 467-473

Simpson MDC, Slater P, Royston MC, Deakin JFW (1992). Regionally selective deficits in uptake sites for glutamate and gamma-aminobutyric acid in the basal ganglia in schizophrenia. Psychiatry Res 42: 273-282.

Smith EE, Jonides J (1999). Storage and executive processes in the frontal lobes. Science 283: 1657-1661.

Smith RE, Haroutunian V, Davis KL, Meador-Woodruff JH (2001a). Expression of excitatory amino acid transporter transcripts in the thalamus of subjects with schizophrenia. Am J Psychiatry 158: 1393-1399.

Smith RE, Haroutunian V, Davis KL, Meador-Woodruff JH (2001b). Vesicular glutamate transporter transcript expression in the thalamus in schizophrenia. Neuroreport 12: 2885-2887.

Spence SA, Grasby PM, Liddle PF, Stefan MD, Sharma T, Murray RM et al (2000). Functional anatomy of verbal fluency in people with schizophrenia and those at genetic risk: focal dysfunction and distributed disconnectivity reappraised. $\mathrm{Br} J$ Psychiatry 176: 52-60. Demonstration of ACC-DLPFC dysconnectivity in schizophrenia.

Stefansson H, Rujescu D, Cichon S, Pietilainen OPH, Ingason A, Steinberg S et al (2008). Large recurrent microdeletions associated with schizophrenia. Nature 455: 232-236

Stefansson H, Sigurdsson E, Steinthorsdottir V, Bjornsdottir S, Sigmundsson T, Ghosh S et al (2002). Neuregulin 1 and susceptibility to schizophrenia. Am J Hum Genet 71: 877-892.

Steinberg JL, Devous Sr MD, Paulman RG (1996). Wisconsin card sorting activated regional cerebral blood flow in first break and chronic schizophrenic patients and normal controls. Schizophr Res 19: 177-187.

Stevens AA, Goldman-Rakic PS, Gore JC, Fulbright RK, Wexler BE (1998). Cortical dysfunction in schizophrenia during auditory word and tone working memory demonstrated by functional magnetic resonance imaging. Arch Gen Psychiatry 55: 1097-1103.

Stirling J, Hellewell J, Blakey A, Deakin W (2006). Thought disorder in schizophrenia is associated with both executive dysfunction and circumscribed impairments in semantic function. Psychol Med 36: 475-484. 
Suddath R, Christison G, Torrey E, Casanova M, Weinberger D (1990). Anatomical abnormalities in the brains of monozygotic twins discordant for schizophrenia. $N$ Engl J Med 322: 789-794.

Suhara T, Okubo Y, Yasuno F, Sudo Y, Inoue M, Ichimiya T et al (2002). Decreased dopamine d2 receptor binding in the anterior cingulate cortex in schizophrenia. Arch Gen Psychiatry 59: 25-30.

Svenningsson P, Nishi A, Fisone G, Girault J-A, Nairn AC, Greengard P (2004). Darpp-32: an integrator of neurotransmission. Annu Rev Pharmacol Toxicol 44 269-296.

Szeszko PR, Bilder RM, Lencz T, Ashtari M, Goldman RS, Reiter G et al (2000). Reduced anterior cingulate gyrus volume correlates with executive dysfunction in men with first-episode schizophrenia. Schizophr Res 43 97-108.

Talvik M, Nordstr\&ouml;m A-L, Olsson H, Halldin C, Farde L (2003). Decreased thalamic d2/d3 receptor binding in drug-naive patients with schizophrenia: a pet study with [11c]flb 457. Int J Neuropsychopharmacol 6: 361-370.

Tan H-Y, Chen Q, Sust S, Buckholtz JW, Meyers JD, Egan MF et al (2007). Epistasis between catechol-o-methyltransferase and type ii metabotropic glutamate receptor 3 genes on working memory brain function. Proc Natl Acad Sci 104: 12536-12541.

Tan H-Y, Choo W-C, Fones CSL, Chee MWL (2005). Fmri study of maintenance and manipulation processes within working memory in first-episode schizophrenia. Am J Psychiatry 162: 1849-1858.

Tan H-Y, Nicodemus KK, Chen Q, Li Z, Brooke JK, Honea R et al (2008). Genetic variation in akt1 is linked to dopamine-associated prefrontal cortical structure and function in humans. J Clin Invest 118: 2200-2208. First demonstration of AKT1-associated differences in frontostriatal circuit structure and function.

Tan H-Y, Sust S, Buckholtz JW, Mattay VS, Meyer-Lindenberg A, Egan MF et al (2006). Dysfunctional prefrontal regional specialization and compensation in schizophrenia. Am J Psychiatry 163: 1969-1977. Key report showing increased ventrolateral versus dorsolateral prefrontal involvement in working memory in schizophrenia.

Tanibuchi I, Goldman-Rakic PS (2003). Dissociation of spatial-, object-, and soundcoding neurons in the mediodorsal nucleus of the primate thalamus. J Neurophysiol 89: 1067-1077.

Theberge J, Bartha R, Drost DJ, Menon RS, Malla A, Takhar J et al (2002). Glutamate and glutamine measured with $4.0 \mathrm{t}$ proton $\mathrm{mrs}$ in never-treated patients with schizophrenia and healthy volunteers. Am J Psychiatry 159: 1944-1946.

Thermenos HW, Goldstein JM, Buka SL, Poldrack RA, Koch JK, Tsuang MT et al (2005). The effect of working memory performance on functional mri in schizophrenia. Schizophr Res 74: 179-194.

Thompson PM, Vidal C, Giedd JN, Gochman P, Blumenthal J, Nicolson R et al (2001). Mapping adolescent brain change reveals dynamic wave of accelerated gray matter loss in very early-onset schizophrenia. Proc Natl Acad Sci USA 98: 11650-11655. Depiction of longitudinal gray matter loss in early-onset schizophrenia.

Tooney PA, Chahl LA (2004). Neurons expressing calcium-binding proteins in the prefrontal cortex in schizophrenia. Prog Neuropsychopharmacol Biol Psychiatry 28: $273-278$

Torrey EF, Barci BM, Webster MJ, Bartko JJ, Meador-Woodruff JH, Knable MB (2005). Neurochemical markers for schizophrenia, bipolar disorder, and major depression in postmortem brains. Biol Psychiatry 57: 252-260. An extensive, cross-diagnostic, cross-regional postmortem study of major psychiatric illness.

Tsuchida A, Fellows LK (2009). Lesion evidence that two distinct regions within prefrontal cortex are critical for $n$-back performance in humans. $J$ Cogn Neurosci advance online publication (doi:10.1162/jocn.2008.21172).

Verhoeff NPLG, Soares JC, D'Souza CD, Gil R, Degen K, Abi-Dargham A et al (1999). [123i]iomazenil spect benzodiazepine receptor imaging in schizophrenia. Psychiatry Res 91: 163-173.

Vernaleken I, Buchholz H-G, Kumakura Y, Siessmeier T, Stoeter P, Bartenstein P et al (2007). Prefrontal cognitive performance of healthy subjects positively correlates with cerebral fdopa influx: an exploratory 18[f]-fluoro-l-dopa-pet investigation. Hum Brain Mapp 28: 931-939.

Volk DW, Austin MC, Pierri JN, Sampson AR, Lewis DA (2000). Decreased glutamic acid decarboxylase67 messenger rna expression in a subset of prefrontal cortical $\backslash\{$ gammal\}-aminobutyric acid neurons in subjects with sch. Arch Gen Psychiatry 57: 237-245.

Volz HP, Gaser C, Hager F, Rzanny R, Mentzel HJ, Kreitschmann-Andermahr I et al (1997). Brain activation during cognitive stimulation with the wisconsin card sorting test-a functional mri study on healthy volunteers and schizophrenics. Psychiatry Res 75: 145-157.
Volz H-P, Gaser C, Häger F, Rzanny R, Pönisch J, Mentzel H-J et al (1999). Decreased frontal activation in schizophrenics during stimulation with the continuous performance test - a functional magnetic resonance imaging study. Eur Psychiatry 14: 17-24

Wager TD, Smith EE (2003). Neuroimaging studies of working memory: a metaanalysis. Cogn Affect Behav Neurosci 3: 255-274.

Wang H-D, Deutch AY (2007). Dopamine depletion of the prefrontal cortex induces dendritic spine loss: reversal by atypical antipsychotic drug treatment Neuropsychopharmacology 33: 1276-1286. Evidence that disruption of ventral tegmental afferents to the prefrontal cortex adversely impacts prefrontal dendritic spine availability, which is ameliorated by atypical but not typical antipsychotic treatment.

Wang X-J, TegnÃr J, Constantinidis C, Goldman-Rakic PS (2004). Division of labor among distinct subtypes of inhibitory neurons in a cortical microcircuit of working memory. Proc Natl Acad Sci USA 101: 1368-1373.

Wei Y, Williams JM, Dipace C, Sung U, Javitch JA, Galli A et al (2007). Dopamine transporter activity mediates amphetamine-induced inhibition of akt through a ca2+/calmodulin-dependent kinase ii-dependent mechanism. Mol Pharmacol 71: 835-842

Weinberger D, Berman K, Suddath R, Torrey E (1992). Evidence of dysfunction of a prefrontal-limbic network in schizophrenia: a magnetic resonance imaging and regional cerebral blood flow study of discordant monozygotic twins. Am J Psychiatry 149: 890-897. First in vivo evidence of link between hippocampal and prefrontal abnormalities in schizophrenia.

Weinberger DR, Aloia MS, Goldberg TE, Berman KF (1994). The frontal lobes and schizophrenia. J Neuropsychiatry Clin Neurosci 6: 419-427.

Weinberger DR, Berman KF, Zec RF (1986). Physiologic dysfunction of dorsolateral prefrontal cortex in schizophrenia. I. Regional cerebral blood flow evidence. Arch Gen Psychiatry 43: 114-124. Key paper showing reliable hypoactivation of DLPFC during executive task performance in schizophrenia.

Weiss AP, DeWitt I, Goff D, Ditman T, Heckers S (2005). Anterior and posterior hippocampal volumes in schizophrenia. Schizophr Res 73: 103-112.

Weiss EM, Golaszewski S, Mottaghy FM, Hofer A, Hausmann A, Kemmler G et al (2003). Brain activation patterns during a selective attention test-a functional mri study in healthy volunteers and patients with schizophrenia. Psychiatry Res 123: $1-15$

Weiss EM, Siedentopf C, Golaszewski S, Mottaghy FM, Hofer A, Kremser C et al (2007). Brain activation patterns during a selective attention test - a functional mri study in healthy volunteers and unmedicated patients during an acute episode of schizophrenia. Psychiatry Res 154: 31-40.

Whitfield-Gabrieli S, Thermenos HW, Milanovic S, Tsuang MT, Faraone SV, McCarley RW et al (2009). Hyperactivity and hyperconnectivity of the default network in schizophrenia and in first-degree relatives of persons with schizophrenia. Proc Natl Acad Sci 106: 1279-1284. Demonstration of reduced task-related suppression of midline 'default network' structures in conjunction with reduced medial and lateral prefrontal 'anticorrelations'.

Wible CG, Lee K, Molina I, Hashimoto R, Preus AP, Roach BJ et al (2009). Fmri activity correlated with auditory hallucinations during performance of a working memory task: data from the fbirn consortium study. Schizophr Bull 35 $47-57$.

Winterer G, Coppola R, Goldberg TE, Egan MF, Jones DW, Sanchez CE et al (2004). Prefrontal broadband noise, working memory, and genetic risk for schizophrenia. Am J Psychiatry 161: 490-500.

Wolf DH, Gur RC, Valdez JN, Loughead J, Elliott MA, Gur RE et al (2007). Alterations of fronto-temporal connectivity during word encoding in schizophrenia. Psychiatry Res 154: 221-232.

Wolf RC, Höse A, Frasch K, Walter H, Vasic N (2008). Volumetric abnormalities associated with cognitive deficits in patients with schizophrenia. Eur Psychiatry 23: $541-548$

Wong DF, Wagner HN, Tune LE, Dannals RF, Pearlson GD, Links JM et al (1986). Positron emission tomography reveals elevated d2 dopamine receptors in drugnaive schizophrenics. Science 234: 1558-1563. Influential paper documenting increased D2 receptors in medication nauml;ve schizophrenia patients, in line with the dopamine hypothesis of psychosis.

Woo T-UW, Walsh JP, Benes FM (2004). Density of glutamic acid decarboxylase 67 messenger rna-containing neurons that express the $n$-methyl-d-aspartate receptor subunit $\mathrm{nr} 2 \mathrm{a}$ in the anterior cingulate cortex in schizophrenia and bipolar disorder. Arch Gen Psychiatry 61: 649-657.

Wood SJ, Yücel M, Wellard RM, Harrison BJ, Clarke K, Fornito A et al (2007). Evidence for neuronal dysfunction in the anterior cingulate of patients with schizophrenia: a proton magnetic resonance spectroscopy study at $3 \mathrm{t}$. Schizophr Res 94: 328-331.

Woodward ND, Waldie B, Rogers B, Tibbo P, Seres P, Purdon SE (2009). Abnormal prefrontal cortical activity and connectivity during response selection in first 
episode psychosis, chronic schizophrenia, and unaffected siblings of individuals with schizophrenia. Schizophr Res 109: 182-190.

Wright IC, Rabe-Hesketh S, Woodruff PWR, David AS, Murray RM, Bullmore ET (2000). Meta-analysis of regional brain volumes in schizophrenia. Am J Psychiatry 157: 16-25.

Yasuno F, Suhara T, Okubo Y, Ichimiya T, Takano A, Sudo Y et al (2005). Abnormal effective connectivity of dopamine d2 receptor binding in schizophrenia. Psychiatry Res 138: 197-207.

Yoon JH, Minzenberg MJ, Ursu S, Walters R, Wendelken C, Ragland JD et al (2008). Association of dorsolateral prefrontal cortex dysfunction with disrupted coordinated brain activity in schizophrenia: relationship with impaired cognition, behavioral disorganization, and global function. Am J Psychiatry 165: 1006-1014.

Yoon U, Lee J-M, Kwon JS, Kim H-P, Shin Y-W, Ha TH et al (2006). An mri study of structural variations in schizophrenia using deformation field morphometry. Psychiatry Res 146: 171-177.

Young C, Arima K, Xie J, Hu L, Beach T, Falkai P et al (1998). Snap-25 deficit and hippocampal connectivity in schizophrenia. Cereb Cortex 8: 261-268.

Yucel M, Pantelis C, Stuart GW, Wood SJ, Maruff P, Velakoulis D et al (2002). Anterior cingulate activation during stroop task performance: a pet to $\mathrm{mri}$ coregistration study of individual patients with schizophrenia. Am J Psychiatry 159: 251-254.

Yurgelun-Todd D, Waternaux C, Cohen B, Gruber S, English C, Renshaw P (1996). Functional magnetic resonance imaging of schizophrenic patients and comparison subjects during word production. Am J Psychiatry 153: 200-205.

Zaidel D, Esiri M, Harrison P (1997). Size, shape, and orientation of neurons in the left and right hippocampus: investigation of normal asymmetries and alterations in schizophrenia. Am J Psychiatry 154: 812-818.

Zetzsche T, Preuss U, Frodl T, Leinsinger G, Born C, Reiser M et al (2008). White matter alterations in schizophrenic patients with pronounced negative symptomatology and with positive family history for schizophrenia. Eur Arch Psychiatry Clin Neurosci 258: 278-284.

Zhou S-Y, Suzuki M, Takahashi T, Hagino H, Kawasaki Y, Matsui M et al (2007). Parietal lobe volume deficits in schizophrenia spectrum disorders. Schizophr Res 89: 35-48.

Zou L-Q, Yuan H-S, Pei X-L, Dong W-T, Liu P-C, Xie J-X (2008). Diffusion tensor imaging study of the anterior limb of internal capsules in neuroleptic-naive schizophrenia. Acad Radiol 15: 285-289. 